\title{
A more accurate scheme for calculating Earth's skin temperature
}

\author{
Ben-Jei Tsuang $\cdot$ Chia-Ying Tu $\cdot$ Jeng-Lin Tsai $\cdot$ \\ John A. Dracup $\cdot$ Klaus Arpe $\cdot$ Tilden Meyers
}

Received: 8 July 2007 / Accepted: 6 October 2008/Published online: 6 November 2008

(C) The Author(s) 2008. This article is published with open access at Springerlink.com

\begin{abstract}
The theoretical framework of the vertical discretization of a ground column for calculating Earth's skin temperature is presented. The suggested discretization is derived from the evenly heat-content discretization with the optimal effective thickness for layer-temperature simulation. For the same level number, the suggested discretization is more accurate in skin temperature as well as surface ground heat flux simulations than those used in some state-of-the-art models. A proposed scheme ("op $(3,2,0)$ ") can reduce the normalized root-mean-square error (or RMSE/STD ratio) of the calculated surface ground heat flux of a cropland site significantly to $2 \%$ (or $0.9 \mathrm{~W} \mathrm{~m}^{-2}$ ), from $11 \%$ (or $5 \mathrm{~W} \mathrm{~m}^{-2}$ ) by a 5-layer scheme used in ECMWF, from $19 \%$ (or $8 \mathrm{~W} \mathrm{~m}^{-2}$ ) by a 5-layer scheme used in ECHAM, and from $74 \%$ (or $32 \mathrm{~W} \mathrm{~m}^{-2}$ ) by a single-layer scheme used in the UCLA GCM. Better
\end{abstract}

B.-J. Tsuang $(\varangle) \cdot$ J.-L. Tsai

Department of Environmental Engineering,

National Chung Hsing University, Taichung 40227, Taiwan

e-mail: tsuang@nchu.edu.tw

C.-Y. Tu

Taiwan Typhoon and Flood Research Institute,

No. 22, Keyuan Rd., Central Taiwan Science Park,

Taichung 40763, Taiwan

J. A. Dracup

Department of Civil and Environmental Engineering,

University of California, Berkeley, USA

K. Arpe

Max-Planck Institute for Meteorology, Hamburg, Germany

T. Meyers

Atmospheric Turbulence and Diffusion Division,

NOAA/ARL, P.O. Box 2456, 456 South Illinois Avenue,

Oak Ridge, TN 37831-2456, USA accuracy can be achieved by including more layers to the vertical discretization. Similar improvements are expected for other locations with different land types since the numerical error is inherited into the models for all the land types. The proposed scheme can be easily implemented into state-of-the-art climate models for the temperature simulation of snow, ice and soil.

Keywords Air-sea interaction · Air-land interaction . Sea surface temperature $\cdot$ Land surface temperature . Snow $\cdot$ Ice $\cdot$ Skin layer $\cdot$ Numerical discretization . PILPS

\section{Introduction}

Land/ocean skin temperature (ST) is an important parameter for quantifying the energy and water vapor exchanges between land/ocean and the atmosphere. In addition, accurate predictions of the time of temperatures reaching melting point for snow surface and ice surface are important factors for determining the times of snow and ice to melt and water to freeze (e.g., Ek et al. 2003). Despite this importance, many state-of-the-art models fail to accurately predict those times of phase changes. For example, ECHAM (Arpe et al. 1994) and SNOBAL (Link and Marks 1999) lag-predict the snow melting time. Furthermore, NCEP (Kanamitsu et al. 2002) and ECMWF (Simmons and Gibson 2000) are unable to predict the ice periods for the ocean grids in the $40-70^{\circ}$ latitude zone (Tsuang et al. 2008). Since 1992, the Project for the Intercomparison of Land Surface Parameterization Schemes (PILPS) (Henderson-Seller 1995) has been systematically intercomparing the performance of land surface schemes (LSSs) (Schlosser 2000; Slater et al. 2001; Luo 
et al. 2003; van den Hurk and Viterbo 2003; Bowling et al. 2003). By contrast, this study tries to conduct a theoretical analysis of the discretization of the skin layer for various LSSs.

This study proposes the following numerical discretizations for calculating $\mathrm{ST}$ (denoted as $T_{0}$ ), ground temperature at level $k\left(T_{\mathrm{k}}\right)$ and the bottom-layer numerical ground temperature $\left(T_{\mathrm{m}}\right)($ Fig. 1$)$ as:
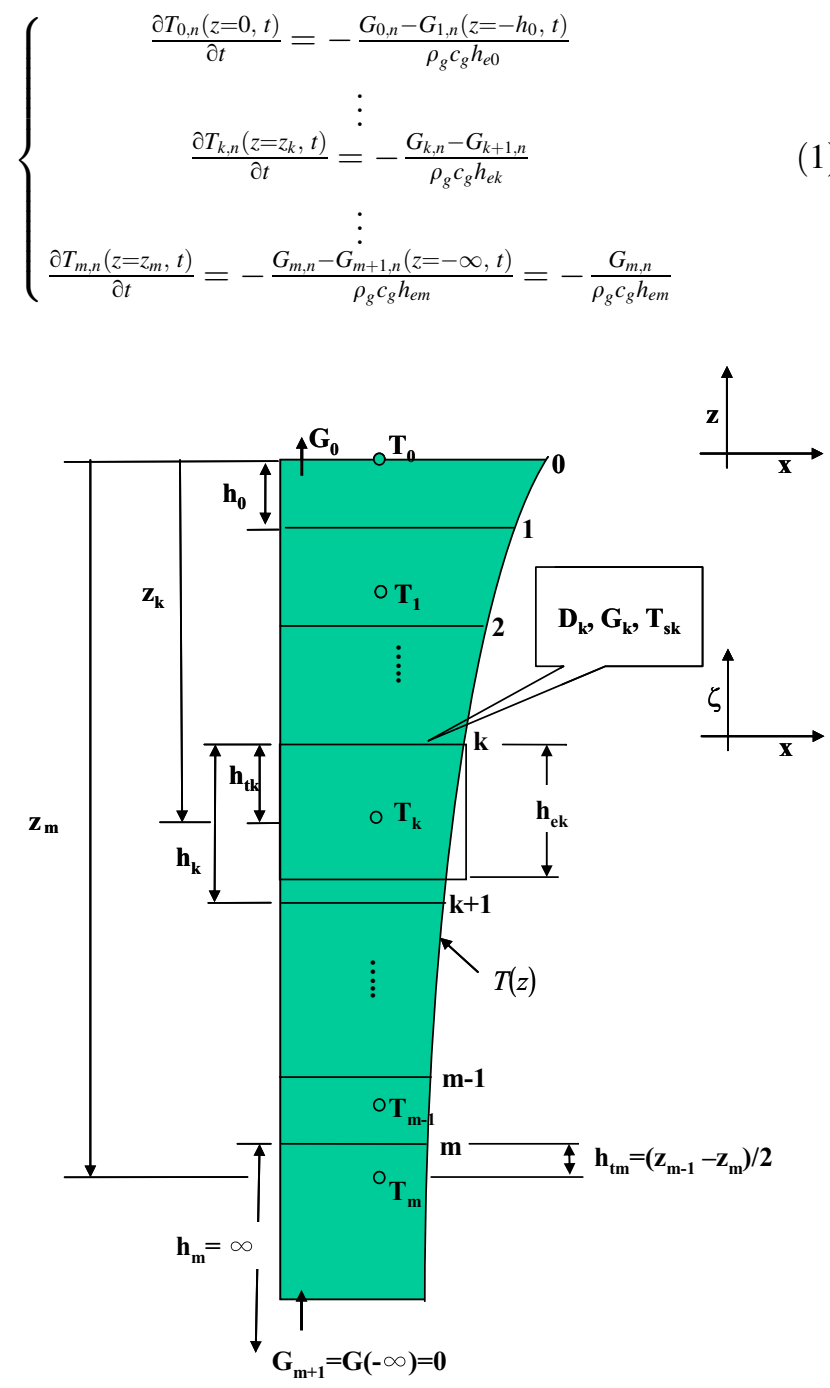

Fig. 1 Grid structure for a ground column of the "op" scheme proposed by this study, where $z_{k}$ is vertical coordinate of ground temperature $T_{k}$. The variables $h_{e 0}, h_{e k}$ and $h_{e m}$ are the effective thicknesses of the skin layer, of the layer $k$, and the bottom layer, respectively. The variables $D_{k}, G_{k}$ and $T_{s k}$ are heat diffusivity, ground heat flux and upper boundary ground temperature of level $k$ at $\zeta=0$, respectively. The origin $(\zeta=0)$ of the vertical coordinate $\zeta$ is located at the location of ground heat flux $G_{k}$. Of the $\zeta$ coordinate, $T_{k}$ is at $\zeta=-h_{t k}$ and $0 \leq h_{t k} \leq h_{k}$. The optimal effective thicknesses $h_{e 0}, h_{e k}$ and $h_{e m}$ are calculated according to Eq. 20, derived by minimizing the error for $T_{0}, T_{k}$ and $T_{m}$ simulations, respectively. It can be seen that the effective thickness $h_{e 0}$ of the skin layer is determined under the conditions that the level index $k=0, h_{\mathrm{t} 0}=0$ and $h_{0}=-z_{1} / 2$, and the effective thickness $h_{e k}$ of layer $k$ is determined under the conditions that $h_{t k}=\left(z_{k-1}-z_{k}\right) / 2$ and $h_{k}=\left(z_{k-1}-z_{k+1}\right) / 2$ where $T_{0, n}, T_{k, n}$ and $T_{m, n}$ are calculated skin temperature, ground temperature at level $k$ and bottom-layer numerical ground temperature $(\mathrm{K})$, respectively; $t$ is time $(\mathrm{s}) ; G_{k, n}$ are calculated ground heat flux at level $k\left(\mathrm{~W} \mathrm{~m}^{-2}\right)$ (positive upward); $\rho_{\mathrm{g}}$ and $c_{\mathrm{g}}$ are density $\left(\mathrm{kg} \mathrm{m}^{-3}\right)$ and specific heat of the surface $\left(\mathrm{J} \mathrm{kg}^{-1} \mathrm{~K}^{-1}\right)$, respectively. The subscript " 0 " denotes a property at the surface, the subscript " $n$ " denotes a property solved by a numerical method, and the subscript " $m$ " denotes a property at the bottom level. The variable $h_{0}$ is the physical thickness of the skin layer, $h_{e 0}$ is the effective thickness of the skin layer, $h_{e k}$ is the effective thickness of the level- $k$ numerical layer, and $h_{e m}$ is the effective thickness of the bottom layer. Note that the physical thickness of the bottom layer is infinity, and the ground heat flux approaches zero at the infinite depth, i.e., $G_{m+1, n}(z=-\infty, t)=0$ (Carslaw and Jaeger 1959). Setting $G_{m+1, n}=0$ is also adopted by a few state-of-the-art climate models, such as by ECMWF (Viterbo and Beljaars 1995) and ECHAM (Roeckner et al. 2003). It is a good boundary condition since surface energy budget can be closed, when compared to a force-restored scheme used in some other climate models (Tsuang 2005; Tsuang et al. 2008). Nonetheless, how to determine $h_{e m}$ is not well documented. Note that $\rho_{g} c_{g} h_{e 0}\left(\mathrm{~J} \mathrm{~m}^{-2} \mathrm{~K}^{-1}\right)$ is also called surface area heat capacity (Grell et al. 1995) or the heat capacity of the surface layer (Roeckner et al. 2003). Similarly, we name $\rho_{g} c_{g} h_{e k}$ as level- $k$ area heat capacity $\left(\mathrm{J} \mathrm{m}^{-2} \mathrm{~K}^{-1}\right)$.

This study tries to derive optimal value for the effective thickness $h_{e k}$ by minimizing the error for the temperature simulation of $T_{k}$. The conventional finite-difference scheme (denoted as "cv") assumes that the ST is equal to the mean-layer temperature of the uppermost finite-difference layer (e.g., Tsuang and Dracup 1990; Gaspar et al. 1990; Blondin 1991; Hostetler et al. 1993; Sellers et al. 1996; Chia and Wu 1998; Link and Marks 1999), which can be calculated by the first equation in Eq. 1 by setting $h_{e 0}=h_{0}$. Nonetheless, it is a well known fact that the calculated amplitude of the ST is dependent on vertical resolution, and the amplitude usually decreases with $h_{0}$ (e.g., Gaspar et al. 1990) unless the thickness of the uppermost numerical layer is discretized infinitely thin (e.g., Mote and O'Neill 2000). Consequently, the diurnal cycle of the surface temperature is poorly simulated. Hence, a time lag for determining the timing of snow melt may be produced. However, an infinitely thin thickness is numerically impossible; and the thinner the thickness, the more the number of numerical layers required and the higher the computational cost. On the other hand, Viterbo and Beljaars (1995) set $h_{e 0}$ at 0 by assuming that the skin layer has no heat capacity (denoted as "nh" scheme); Oleson et al. (2004) set $h_{e 0}$ at a value $<h_{0}$. Various studies have been conducted to find a suitable discretization to compromise 
Table 1 Comparison of skin-layer parameterizations in the literature, where $k=$ heat diffusivity, $\omega=$ diurnal angular velocity

\begin{tabular}{|c|c|c|c|c|c|}
\hline Model name & Levels & $\begin{array}{l}\text { Physical skin-layer } \\
\text { thickness } h_{0}\left(h_{0}^{*}\right)\end{array}$ & $\begin{array}{l}\text { Effective skin-layer } \\
\text { thickness } h_{\mathrm{e} 0}\left(h_{e 0}^{*}\right)\end{array}$ & Type & Ref. \\
\hline UCLA, SiB (A74) & 1 & $\infty$ & $\sqrt{D / \omega_{d}}(1 / \sqrt{2})$ & ne & $\begin{array}{l}\text { Arakawa and Mintz (1974), } \\
\text { Sellers et al. (1986) }\end{array}$ \\
\hline D78 & 1 & $\infty$ & $\sqrt{2 D / \omega_{d}}(1)$ & on & Deardorff (1978) \\
\hline $\begin{array}{l}\text { Force-restored } \\
\text { scheme, } \mathrm{SiB} 2\end{array}$ & Multiple & $\sqrt{D / 2 \omega_{d}}(0.5)$ & $=h_{0}(0.5)$ & $\mathrm{cv}$ & $\begin{array}{l}\text { Deardorff (1978), } \\
\text { Sellers et al. (1996) }\end{array}$ \\
\hline MM5 & Multiple & $0.89 \sqrt{D / 2 \omega_{d}}(0.445)$ & $0.95 \sqrt{D / 2 \omega_{d}}(0.475)$ & $\mathrm{n} / \mathrm{a}$ & Grell et al. (1995) \\
\hline ECMWF CY47 & Multiple & $7.2 \mathrm{~cm}(\sim 0.55)$ & $=h_{0}(\sim 0.55)$ & $\mathrm{cv}$ & Blondin (1991) \\
\hline ECMWF CY48 & Multiple & $1.75 \mathrm{~cm}(\sim 0.13)$ & 0 & $\mathrm{cv}+\mathrm{nh}$ & Viterbo and Beljaars (1995) \\
\hline ECHAM5 & Multiple & $6.5 \mathrm{~cm}(\sim 0.5)$ & $=h_{0}$ & $\mathrm{cv}$ & Roeckner et al. (2003) \\
\hline CLM & Multiple & $1.75 \mathrm{~cm}(\sim 0.13)$ & $0.83 \mathrm{~cm}(\sim 0.064)$ & $\mathrm{n} / \mathrm{a}$ & Oleson et al. (2004) \\
\hline This study & Multiple & $1.878 \mathrm{~cm}(\sim 0.14)$ & $h_{e 0}^{p}(\sim 0.134)$ & $o p(3,2,0)$ & \\
\hline
\end{tabular}

$D$ heat diffusivity, $\omega_{\mathrm{d}}$ diurnal angular velocity

The types "ne", "on", "cv" and "nh" denote the Non-stiff Equal-amplitude scheme, the Optimal Non-stiff scheme, the ConVentional finitedifference scheme and the No Heat capacity scheme, respectively

between the accuracy and the computational cost as summarized in Table 1 (Viterbo and Beljaars 1995; Chen and Dudhia 2001; Roeckner et al. 2003; Oleson et al. 2004).

Minimizing the error for calculating the ST of the dominant frequency component leads to an optimal effective thickness while calculating the ST. The optimal effective thickness of a single-layer discretization $\left(h_{0} \rightarrow \infty\right)$ for a soil column has been introduced by Arakawa and Mintz (1974) (denoted as A74) and Deardorff (1978) (denoted as D78). A74 has been adopted in many land surface parameterizations (Sellers et al. 1986; Tsuang and Yuan 1994; Tsuang and Tu 2002). Tsuang (2003), based on it, derived an analytical solution set for describing both land skin temperature and Planetary Boundary Layer air temperature. Tsuang (2005) reformulated the equation to determine surface ground heat flux from land skin temperature retrieved from satellites.

Since A74 and D78 use only a single layer for representing a soil column, they are very economical. Nonetheless, their accuracies have limitations. Recently, many state-of-the-art land surface parameterizations have started to simulate temperatures at multiple ground layers such as the force-restored scheme (also proposed by Deardorff 1978) used in SiB2 (Sellers et al. 1996), ECHAM (Roeckner et al. 2003), ECMWF (Blondin 1991; Viterbo and Beljaars 1995), MM5 (Grell et al. 1995), NOAH (Chen and Dudhia 2001) and CLM (Oleson et al. 2004; Dickinson et al. 2006). This study extends A74 and D78's work from single-layer discretization to multiplelayer discretization to further increase accuracy.

Earlier versions of the proposed scheme have been applied for the determination of the phase changes for snow, ice and water by implementing it into a climate model (Tsuang et al. 2001) and a turbulent kinetic energy ocean model (Tu and Tsuang 2005). Chen and Dudhia (2001) and Oleson et al. (2004) also implemented similar concept into their models. Nonetheless, so far these numerical schemes have not been well documented and analyzed.

\section{Optimal effective thickness}

This section tries to determine the optimal value of the effective thickness (denoted as $h_{e k}^{p}$ ) of layer $k$ under the conditions that the true ground heat fluxes $\left(G_{k}, G_{k+1}\right)$ at $\zeta=0$ and $\zeta=-h_{k}$ are known. Nonetheless, it should be noted that due to numerical error, the calculated ground heat fluxes $\left(G_{k, n}, G_{k+1, n}\right)$ can be departed from their true fluxes. In this section, the vertical coordinate system $\zeta$ is used, where the origin $(\zeta=0)$ of $\zeta$ is at $G_{k}$ (Fig. 1). Then, the ground temperature $T_{k}$ can be determined as:

$$
\frac{\partial T_{k, n}\left(\zeta=-h_{t}, t\right)}{\partial t}=-\frac{G_{k, n}(\zeta=0, t)-G_{k+1, n}\left(\zeta=-h_{k}, t\right)}{\rho_{g} c_{g} h_{e k}}
$$

where $h_{e k}$ is the effective thickness of layer $k, T_{k}$ is the temperature at depth $h_{t}$ below $G_{k}$. From Fig. 1 (or Eq. 1), it can be seen that $T_{0}$ is determined under the conditions $k=0, h_{t}=0$ and $h_{0}=-z_{1} / 2$, of which the effective thickness of the skin layer is $h_{e 0} ; T_{k}$ is determined under the conditions $h_{t}=\left(z_{k-1}-z_{k}\right) / 2$ and $h_{k}=\left(z_{k-1}-z_{k+1}\right) / 2$, of which the effective thickness is $h_{e k}$; and, $T_{\mathrm{m}}$ is determined under the conditions $k=m, h_{t}=\left(z_{m-1}-z_{m}\right) / 2$ and $h_{m}=\infty$, of which the effective thickness of the bottom layer is $h_{e m}$.

It should be noted that the solutions of the true ground temperature profile and the true ground heat flux profile of a ground column can be determined analytically under the conditions that for an ideal surface, in which the heat 
diffusion coefficient $D$ is constant and neglecting the horizontal heat transport, the heat transfer in the ground can be assumed to obey the Fourier law of diffusion, and the upper boundary temperature can be expressed in the Fourier series (e.g., Tsuang 2003). Please refer to Appendix 1 for further details. Under the above conditions, the true profiles of ground temperature and heat flux within a ground column can be described analytically as shown in Eqs. 36 and 38 , respectively, of which the upper boundary temperature $T_{s k}$ is written as:

$T_{s k}=\overline{T_{s k}}+\sum_{j=1}^{j=\infty} \Delta T_{s k j} \cos \left(\omega_{j}\left(t-t_{k m j}\right)\right)$

where the overbar " " " is the average, the subscript " $j$ " denotes a property of frequency component $j, \Delta T_{s k j}$ is the amplitude of the $T_{s k}$ of the particular frequency component, $\omega_{j}$ is the angular velocity of the frequency component, $t_{k m j}$ is the time when the highest $T_{s k}$ of the particular frequency component occurs, and $t$ is local time. Moreover, the surface ground heat flux $G_{0}$ can also be determined from the energy budget of the land surface, where outgoing terrestrial radiation, surface sensible heat flux and surface latent heat flux are functions of ST (e.g., Brutsaert 1982; Garratt 1992). That is, $G_{0}$ is a function of $T_{0}$. Similarly the subsurface ground heat fluxes $G_{k}(k>0)$ and $G_{k+1}$ are also a function of $T_{k}$, according to the Fourier law of diffusion. Hence, the error in calculated $T_{k}$ causes an error in simulated $G_{k}$ and $G_{k+1}$, which in turn changes the simulated $T_{k}$. It is assumed that the optimization can be done layer by layer, and only the dependencies of the heat fluxes $G_{k}$ and $G_{k+1}$ with respect to $T_{k}$ are considered. The temperatures of the level above and below are ignored. Then, the relation between calculated $G_{k, n}$ and $G_{k+1, n}$ can be related to their respective true fluxes $G_{k}$ and $G_{k+1}$ (Eq. 38) at $\zeta=0$ and $-h_{k}$, respectively, by Taylor's series expansion on $T_{k}$ as:

$$
\left\{\begin{aligned}
G_{k, n}\left(T_{k, n}\right)= & G_{k}\left(T_{k}\right)+\frac{\partial G_{k}}{\partial T_{k}}\left(T_{k, n}-T_{k}\right)+\text { H.O.T. } \\
= & G(\zeta=0)+x_{k}\left(T_{k, n}-T\left(\zeta=-h_{t}\right)\right) \\
& + \text { H.O.T. } \\
G_{k+1, n}\left(T_{k, n}\right)= & G_{k+1}\left(T_{k}\right)+\frac{\partial G_{k+1}}{\partial T_{k}}\left(T_{k, n}-T_{k}\right)+\text { H.O.T. } \\
= & G\left(\zeta=-h_{k}\right)-x_{k+1}\left(T_{k, n}-T\left(\zeta=-h_{t}\right)\right) \\
& + \text { H.O.T. }
\end{aligned}\right.
$$

where $T_{k, n}$ is the simulated $T_{k}(\mathrm{~K})$. Note that $G_{k}=G(\zeta=0), \quad G_{k+1}=G\left(\zeta=-h_{k}\right) \quad$ and $\quad T_{k}=T(\zeta=$ $\left.-h_{t}\right)$. The second term shows the difference between calculated and true ground heat flux, and $x_{k}$ is defined (Refer to Appendix 2 for the derivation) as:

$$
\begin{aligned}
& x_{0}=\frac{\partial G_{0}\left(T_{0}\right)}{\partial T_{0}}=4 \varepsilon \sigma T_{0}^{3}+\frac{\rho_{a} c_{a}}{r_{a}}+\frac{\rho_{a} L_{v}}{r_{a}+r_{c}} \frac{\partial q^{*}\left(T_{0}\right)}{\partial T_{0}} \\
& x_{k}=-\frac{\partial G_{k}}{\partial T_{k-1}}=\frac{\partial G_{k}}{\partial T_{k}}=\frac{\rho_{g} c_{g} D}{z_{k-1}-z_{k}}, \quad k=1, m \\
& x_{m+1}=-\frac{\partial G_{m+1}}{\partial T_{m}}=\frac{\rho_{g} c_{g} D}{z_{m}-z_{m+1}}=\frac{\rho_{g} c_{g} D}{z_{m}+\infty}=0
\end{aligned}
$$

where $\varepsilon$ is emissivity of surface; $\sigma$ is Stefan-Boltzman constant $\left(\sim 5.67 \times 10^{-8} \mathrm{~W} \mathrm{~m}^{-2} \mathrm{~K}^{-4}\right) ; \quad \rho_{\mathrm{a}}$ and $c_{\mathrm{a}}$ are density $\left(\sim 1.16 \mathrm{~kg} \mathrm{~m}^{-3}\right)$ and constant pressure heat capacity $\left(\sim 1,005 \mathrm{~J} \mathrm{~kg}^{-1} \mathrm{~K}^{-1}\right)$ of air, respectively; $q^{*}(T)$ is saturated specific humidity at temperature $T\left(=0.622 e^{*}(T) /\right.$ $P$ ), where $P$ is atmospheric pressure $(\mathrm{Pa})$ and $e^{*}$ is saturated vapor pressure $(\mathrm{Pa})$ (Richards 1971); $r_{\mathrm{a}}$ is aerodynamic resistance $\left(\mathrm{s} \mathrm{m}^{-1}\right) ; r_{\mathrm{c}}$ is canopy resistance $\left(\mathrm{s} \mathrm{m}^{-1}\right)$ for evapotranspiration; and $L_{\mathrm{v}}$ is latent heat of evaporation $\left(\sim 2.5 \times 10^{6} \mathrm{~J} / \mathrm{kg}\right)$. Note that the third equality of Eq. $5 \mathrm{c}$ is derived due to that $z_{m+1} \rightarrow-\infty$. Figure 2 shows $\partial G_{0} / \partial T_{0}$ as a function of ST for various aerodynamic and canopy resistances with $\varepsilon=0.97$ and $P=1,013 \mathrm{hPa}$. It can be seen that $\partial G_{0} / \partial T_{0}$ increases with $\mathrm{ST}$, but decreases with aerodynamic and canopy resistances. In general, during the daylight hours, aerodynamic and canopy resistances are much lower than those during the nights (Blondin 1991; Tsai et al. 2007). Typical values of daytime aerodynamic and canopy resistances observed in various land covers in the summer can be found in Wilson et al. (2002). Therefore, from the Fig. 2, we can infer that the values of $\partial G_{0} / \partial T_{0}$ during summer days are much higher than those during winter nights.
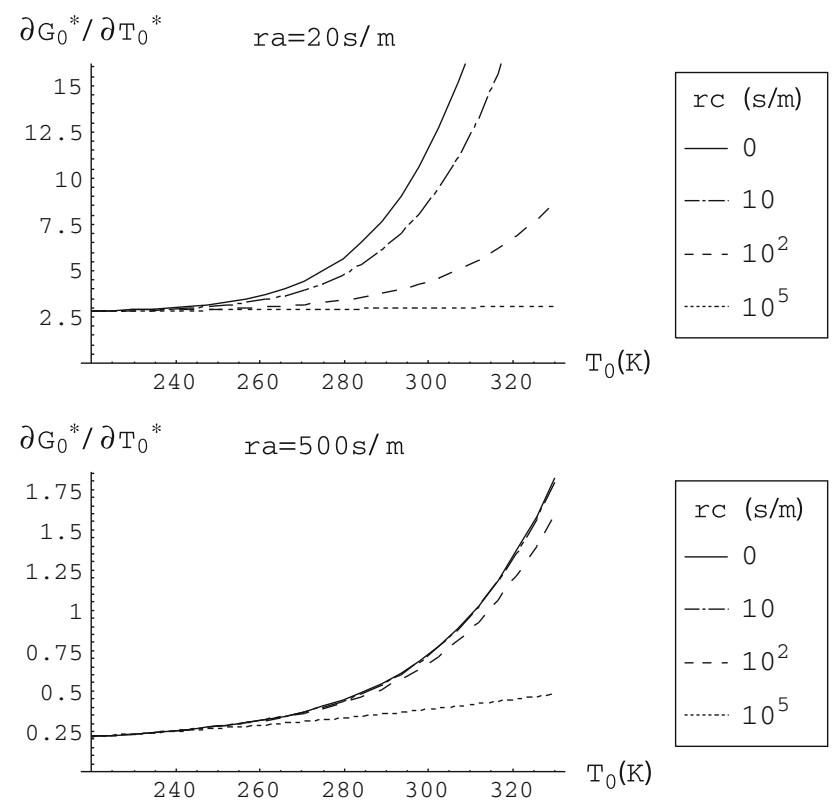

Fig. $2 \partial G_{0} / \partial T_{0}$ as a function of skin temperature $\left(T_{0}\right)$ for various aerodynamic resistances $\left(r_{\mathrm{a}}\right)$ and canopy resistances $\left(r_{\mathrm{c}}\right)$ with $\varepsilon=0.97$ and $P=1,013 \mathrm{hPa}$ 
Substituting Eq. 4 into Eq. 2 and neglecting the high order terms (H.O.T.), the governing Eq. 2 can be rewritten as:

$$
\begin{aligned}
\frac{\partial T_{k, n}}{\partial t}= & -\frac{G_{k, n}-G_{k+1, n}}{\rho_{g} c_{g} h_{e k}} \\
= & \frac{-1}{\rho_{g} c_{g} h_{e k}}\left[G_{k}-G_{k+1}+s_{k}\left(T_{k, n}-T_{k}\right)+\text { H.O.T. }\right] \\
= & \frac{-1}{\rho_{g} c_{g} h_{e k}}\left[G(\zeta=0, t)-G\left(\zeta=-h_{k}, t\right)\right. \\
& \left.+s_{k}\left(T_{k, n}-T\left(\zeta=-h_{t}, t\right)\right)+\text { H.O.T. }\right]
\end{aligned}
$$

where the elasticity $s_{k}$ is defined as:

$s_{k} \equiv\left(\frac{\partial G_{k}}{\partial T_{k}}-\frac{\partial G_{k+1}}{\partial T_{k}}\right)=x_{k}+x_{k+1}$

Hereafter, we denote the condition $s_{k} \rightarrow \infty$ as the "stiff" condition, and the condition $s_{k} \rightarrow 0$ as the "nonstiff" condition, borrowing the expressions from massspring system. Under the stiff condition, the restoring forcing $\left(s_{k}\right)$ is large, which forces $T_{k, n} \rightarrow T_{k}$ according to Eq. 6. Under the non-stiff condition, the restoring forcing $\left(s_{k}\right)$ is weak and $T_{k, n}$ can be very different from $T_{k}$.

The simulated $T_{k}$ can also be written in the frequency domain as:

$T_{k, n}=\overline{T_{k, n}}+\sum_{j=1}^{j=\infty} \Delta T_{k j, n} \cos \left(\omega_{j}\left(t-t_{k m j}-t_{k l j}\right)\right)=\sum_{j=0}^{j=\infty} \tau_{k j, n}$

where $\overline{T_{k, n}}$ and $t_{l j}$ are the mean value and the time lag of the simulated $T_{k}$, respectively. From the second equality, it can be observed that for $j=0, \tau_{k 0, n}=\overline{T_{k, n}}$, but $j \geq 1, \tau_{k j, n}=\Delta \mathrm{T}_{k j, n} \cos \left(\omega_{j}\left(t-t_{k m j}-t_{k l j}\right)\right)$. Substituting Eqs. 36, 38 and 8 into Eq. 6 and neglecting the H.O.T., the governing Eq. 6 can be rewritten in the frequency domain as:

$$
\begin{aligned}
& \sum_{j=0}^{j=\infty} {\left[\frac{\partial \tau_{k j, n}}{\partial t}+\frac{s_{k}}{\rho_{g} c_{g} h_{e k}} \tau_{k j, n}\right]=-\frac{1}{\rho_{g} c_{g} h_{e k}} } \\
& \quad \times \sum_{j=0}^{j=\infty}\left[g_{j}(\zeta=0, t)-g_{j}\left(\zeta=-h_{k}, t\right)-s_{k} \tau_{j}\left(\zeta=-h_{t}, t\right)\right]
\end{aligned}
$$

where $g_{j}(\zeta, t)$ and $\tau_{j}(\zeta, t)$ are true ground heat flux and true ground temperature of frequency component $j$, respectively. Please refer to Eqs. 39 and 37 for details. Due to the orthogonal property between different frequency components (Kreyszig 2006), the above governing equation for determining $T_{k}$ by a numerical method can be decomposed for each frequency component into:

$$
\begin{aligned}
& \frac{\partial \tau_{k j, n}}{\partial t}+\frac{s_{k}}{\rho_{g} c_{g} h_{e k}} \tau_{k j, n}=-\frac{1}{\rho_{g} c_{g} h_{e k}} \\
& \quad \times\left[g_{j}(\zeta=0, t)-g_{j}\left(\zeta=-h_{k}, t\right)-s_{k} \tau_{j}\left(\zeta=-h_{t}, t\right)\right]
\end{aligned}
$$

Note that from the above equation, it can be solved that for $j=0, \quad \tau_{k 0, n}=\overline{T_{k, n}}=\tau_{0}\left(\zeta=-h_{t}, t\right)=\overline{T_{k}}$ since $\partial \tau_{k 0, n} / \partial t=g_{0}(\zeta=0, t)=g_{0}\left(\zeta=-h_{k}, t\right)=0$. Note from Eq. 36, it can be derived that $\overline{T_{k}}=\overline{T_{s k}}$. For $j \geq 1$, the solution of $\tau_{k j, n}$ is more complicated and has been solved in Appendix 3.

The overall RMSE of the calculated $T_{k}$ (denoted as $e\left(T_{k}\right)$ ), according to its definition, can be written as:

$$
\begin{aligned}
e\left(T_{k}\right)^{2} & \equiv \overline{\left(T_{k, n}-T_{k}\right)^{2}}=\sum_{j} \overline{\left(\tau_{k j, n}-\tau_{j}\left(\zeta=-h_{t}, t\right)\right)^{2}} \\
& =\sum_{j} e\left(\tau_{k j}\right)^{2}
\end{aligned}
$$

where the second equality is derived due to the orthogonal property between different frequency components (Kreyszig 2006). According to Appendix 3, the normalized rootmean-square error (NRMSE) (or RMSE/STD ratio) $e\left(\tau^{*}\right)$ of the calculated $T_{k, n}$ of the frequency component compared to the true $T_{k}$ can be determined from Eq. 66 as:

$e\left(\tau^{*}\right)=\sqrt{\frac{h_{a}^{* 2}-2 h_{a}^{*} h_{e}^{*} \exp \left(-h_{t}^{*}\right) \cos \left(t_{a}^{*}-h_{t}^{*}\right)+\exp \left(-h_{t}^{*}\right)^{2} h_{e}^{* 2}}{h_{e}^{* 2}+0.5 s^{* 2}}}$

where the asterisks denote the nondimensional variables of the frequency component $j$ at the level $k$. The variables are made nondimensional, by multiplying time by the angular velocity $\omega_{\mathrm{j}}$ of the frequency component, dividing the length by $\sqrt{2 D / \omega_{j}}$, dividing energy flux by the standard deviation (STD) of the ground heat flux component $g_{k j}$ at the upper boundary $(\zeta=0)$, i.e., $g_{k j \mathrm{STD}}$, and dividing temperature component $\tau_{k j}$ by its STD at the upper boundary $(\zeta=0)$, i.e., $\tau_{k j \mathrm{STD}}$. That is:

$$
\begin{aligned}
\tau^{*} & \equiv \frac{\tau_{k j}}{\tau_{k j \mathrm{STD}}}=\frac{\sqrt{2} \tau_{k j}}{\Delta T_{s k j}} \\
h_{e}^{*} & \equiv \frac{h_{e k}}{\sqrt{2 D / \omega_{j}}}
\end{aligned}
$$

$h_{a}^{*}\left(h^{*}\right)=\frac{1}{\sqrt{2}} \sqrt{1-2 \cos \left(h^{*}\right) \exp \left(-h^{*}\right)+\exp \left(-h^{*}\right)^{2}}$

$h_{t}^{*} \equiv \frac{h_{t}}{\sqrt{2 D / \omega_{j}}}$

$s^{*} \equiv \frac{\tau_{k j \mathrm{STD}}}{g_{k j \mathrm{STD}}} s_{k}=\frac{1}{\rho_{g} c_{g} \sqrt{D \omega_{j}}} s_{k}$ 
$t_{a}^{*}\left(h^{*}\right) \equiv \omega_{j} t_{a}\left(h^{*}\right)=\frac{\pi}{4}-\tan ^{-1}\left(\frac{\exp \left(-h^{*}\right) \sin \left(h^{*}\right)}{1-\exp \left(-h^{*}\right) \cos \left(h^{*}\right)}\right)$

where $h^{*} \equiv h_{k} / \sqrt{2 D / \omega_{j}}$. Note that $\tau_{k j \mathrm{STD}}=\Delta T_{s k j} / \sqrt{2}$ and $g_{k j \mathrm{STD}}=\rho_{g} c_{g} \sqrt{D \omega_{j}} \Delta T_{s k j} / \sqrt{2}$ according to Eqs. 41 and 42 , respectively. It shows that $e\left(\tau^{*}\right)$ is a function of $h^{*}, h_{e}^{*}, h_{t}^{*}$ and $s^{*}$ only. Note that $h_{a}^{*}$ and $t_{a}^{*}$ are functions of $h^{*}$ according to Eqs. 15 and 18, respectively. This study tries to determine a better value for $h_{e k}$, of which the rootmean-square error (RMSE) of the calculated ground temperature $T_{k, n}$ of the dominant frequency component $j$ is minimal. That is,

$\min _{h_{e k}} e\left(\tau_{k j}\right)$

Solving the above equation, the optimal value of the effective thickness (denoted as $h_{e k}^{p}$ ) can be determined. Please refer to Appendix 3 for the derivation. And its dimensionless form is written (denoted as $h_{e}^{p^{*}}$ ) as:

$$
\begin{aligned}
e\left(G_{0}\right)^{2} & \equiv \overline{\left(G_{0, n}-G_{0}\right)^{2}}=\sum_{j} \overline{\left(g_{0 j, n}-g_{0 j}\right)^{2}}=\sum_{j} e\left(g_{0 j}\right)^{2} \\
& \approx\left(\frac{\partial G_{0}}{\partial T_{0}}\right)^{2} \sum_{j} e\left(\tau_{0 j}\right)^{2}
\end{aligned}
$$

It implies that while the error of the simulated ST of the dominant frequency component is minimal, the error of the simulated $G_{0}$ of the frequency component is also minimal. Neglecting the H.O.T. and under the conditions that the true ground heat fluxes $\left(G_{0}, G_{1}\right)$ at $z=0$ and $z=-h_{0}$ are known, the NRMSE of the calculated surface ground heat flux $e\left(g_{0}^{*}\right)$ of a frequency component compared to the true flux can be derived from Eq. 23, by substituting Eqs. 12 and 21 into it, as:

$h_{e}^{p *} \equiv \frac{h_{e k}^{p}}{\sqrt{2 D / \omega_{j}}}=\frac{2 h_{a}^{* 2}-\exp \left(-h_{t}^{*}\right)^{2} s^{* 2}+\sqrt{4 h_{a}^{* 4}+4 \cos 2\left(t_{a}^{*}-h_{t}^{*}\right) \exp \left(-h_{t}^{*}\right)^{2} h_{a}^{* 2} s^{* 2}+\exp \left(-h_{t}^{*}\right)^{4} s^{* 4}}}{4 \cos \left(t_{a}^{*}-h_{t}^{*}\right) \exp \left(-h_{t}^{*}\right) h_{a}^{*}}$

We name the numerical scheme, which sets $h_{e}^{*}=h_{e}^{p^{*}}$, as the optimal scheme, proposed by this study (denoted as "op") to calculate ground temperature at each numerical layer. For the skin layer, the optimal effective thickness $h_{e 0}$ can be determined by putting level index $k=0$ and $h_{\mathrm{t}}=0$ into Eq. 20 (Fig. 1b) as:

$h_{e 0}^{p *}=\frac{2 h_{a 0}^{* 2}-s_{0}^{* 2}+\sqrt{4 h_{a 0}^{* 4}+4 \cos \left(2 t_{a 0}^{*}\right) h_{a 0}^{* 2} s_{0}^{* 2}+s_{0}^{* 4}}}{4 \cos \left(t_{a 0}^{*}\right) h_{a 0}^{*}}$

where the subscript " 0 " denotes a property of the skin layer. For the bottom-numerical layer, the effective thickness $h_{e m}$ can be determined by putting level index $k=m$ and $h_{m}=\infty$ into Eq. 20 (Fig. 1c) as:

$$
\begin{aligned}
e\left(g_{0}^{*}\right) & \approx \sqrt{\overline{\left[\frac{\partial G_{0}^{*}}{\partial T_{0}^{*}}\left(\tau_{0, n}^{*}-\tau_{0}^{*}\right)\right]^{2}}}=\frac{\partial G_{0}^{*}}{\partial T_{0}^{*}} \sqrt{\overline{\left[\left(\tau_{0, n}^{*}-\tau_{0}^{*}\right)\right]^{2}}} \\
& =\frac{\partial G_{0}^{*}}{\partial T_{0}^{*}} e\left(\tau_{0}^{*}\right)=\frac{\partial G_{0}^{*}}{\partial T_{0}^{*}} \sqrt{\frac{h_{a 0}^{* 2}-2 h_{a 0}^{*} h_{e 0}^{*} \cos \left(t_{a 0}^{*}\right)+h_{e 0}^{* 2}}{h_{e 0}^{* 2}+0.5 s_{0}^{* 2}}}
\end{aligned}
$$

where $h_{t}^{*}=0$ for the skin layer. It shows that $e\left(g_{0}^{*}\right)$ is a function of $h_{0}^{*}, h_{e 0}^{*}, k_{0}^{*}$ and $\partial G_{0}^{*} / \partial T_{0}^{*}$ only. Note that $h_{a 0}^{*}$ is a function of $h_{0}^{*}$.

Figure 3 shows the accuracies $e\left(g_{0}^{*}\right)$ of the "A74", "D78", "cv", "nh" and "op" schemes as functions of $h_{0}^{*}$ under $\partial G_{0}^{*} / \partial T_{0}^{*}=4$ and 0.5 . The $e\left(g_{0}^{*}\right)$ of the "cv", "nh"

$h_{e m}^{p *}=\frac{1-\exp \left(-h_{t m}^{*}\right)^{2} s_{m}^{* 2}+\sqrt{1+2 \sin \left(2 h_{t m}^{*}\right) \exp \left(-h_{t m}^{*}\right)^{2} s_{m}^{* 2}+\exp \left(-h_{t m}^{*}\right)^{4} s_{m}^{* 4}}}{2 \sqrt{2} \cos \left(\pi / 4-h_{t m}^{*}\right) \exp \left(-h_{t m}^{*}\right)}$

where the subscript " $m$ " denotes a property of the bottom numerical layer, $h_{a m}^{*}(\infty) \rightarrow 1 / \sqrt{2}$, and $t_{a m}^{*}(\infty)=\pi / 4$.

Moreover, under the condition that $\partial G_{0} / \partial T_{0}$ is constant, the RMSE of the calculated surface ground heat flux (denoted as $e\left(G_{0}\right)$ ) can be derived from Eq. 5a by neglecting the H.O.T. as: and "op" schemes are calculated from Eq. 24 by setting $h_{e 0}^{*}$ at $h_{0}^{*}, 0$ and $h_{e 0}^{p^{*}}$, respectively. The $e\left(g_{0}^{*}\right)$ of the "A74" and "D78" schemes are calculated from Eq. 24 by setting $h_{e 0}^{*}$ at $1 / \sqrt{2}$ and 1 , respectively, under the condition $h_{0}^{*} \rightarrow \infty$. This figure shows that for the same $h_{0}^{*}$, the NRMSE simulated by "op" is always the lowest among all 

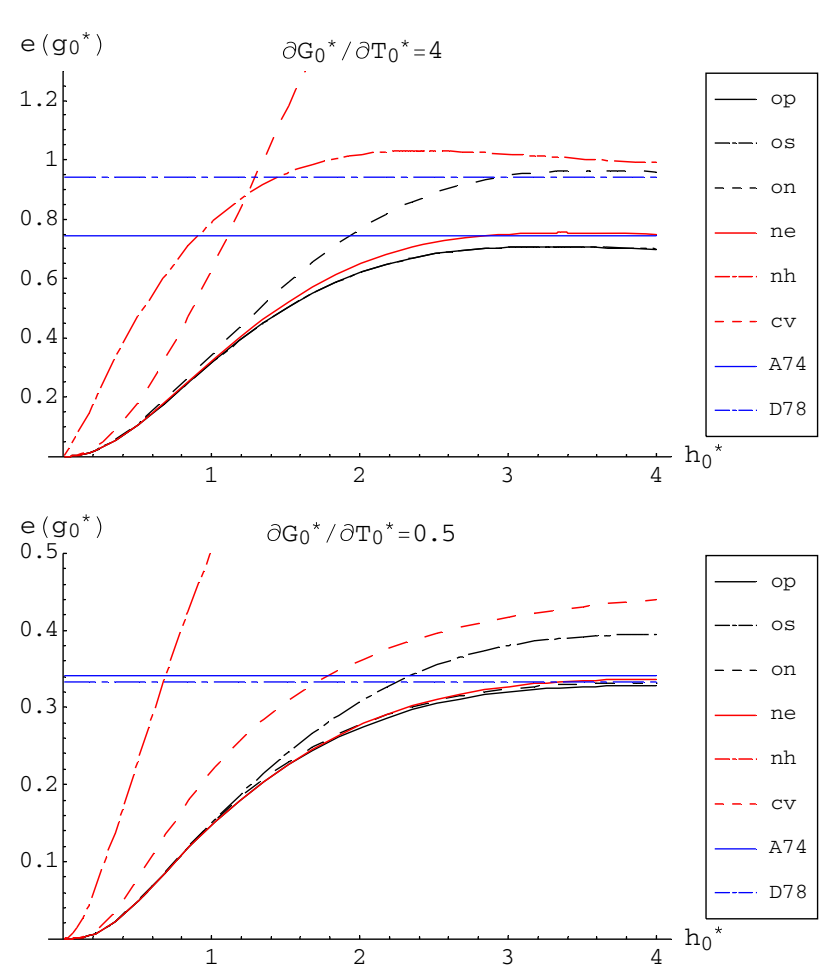

Fig. 3 Normalized root-mean-square errors (or RMSE/STD ratios) $e\left(g_{0}^{*}\right)$ of the surface ground heat flux of a particular frequency, as functions of $h_{0}^{*}$, under the conditions that the true ground heat fluxes $\left(G_{0}, G_{1}\right)$ at surface $(z=0)$ and at $z=-h_{0}$ are known, for $\partial G_{0}^{*} /$ $\partial T_{0}^{*}=4$ and 0.5 as determined by the optimal scheme (denoted as "op"), the optimal stiff scheme (denoted as "os"), the non-stiff equalamplitude scheme (denoted as "ne"), the optimal non-stiff scheme (denoted as "on"), the conventional finite-difference scheme ("cv"), the no-heat capacity scheme ("nh"), the single-layer scheme of Arakawa and Mintz (1974) ("A74") and the single-layer scheme of Deardorff (1978) ("D78”)

the schemes. This is expected since we derive "op" by minimizing the NRMSE. In addition, it shows that the NRMSEs of "cv", "nh" and "op" decrease with thinner $h_{0}^{*}$. Therefore, for achieving a higher accuracy of "op", a finer thickness of the skin layer is needed. In contrast, the accuracy of the single layer schemes "A74" and "D78" are about as good as "op", and better than "cv" and "nh" when $h_{0}^{*}$ is thick $(>2)$. Surprisedly, from the figure, when $h_{0}^{*}<1$, the accuracy of " $\mathrm{nh}$ " is worse than "cv". It implies that using a thinner top layer or inclusion of an infinite thin skin layer like Viterbo and Beljaars (1995) showed a worse behavior than the standard "cv" method. This implies that when $h_{0}^{*}<1$, it is rather calculating the skin temperature by the standard "cv" method than the "nh" scheme.

\section{Vertical discretization for single frequency component}

In the above section, the optimal effective thickness $h_{e k}^{p^{*}}$ has been determined for each numerical layer $k$ under the conditions that $z_{k-1}^{*}, z_{k}^{*}, z_{k+1}^{*}$ are known. Note that $h_{k}^{*}=0.5\left(z_{k-1}^{*}-z_{k+1}^{*}\right)$ and $h_{t k}^{*}=0.5\left(z_{k-1}^{*}-z_{k}^{*}\right)$. In addition, the accuracy $e\left(g_{0}^{*}\right)$ (Eq. 24) is derived under the conditions that the true ground heat fluxes at $z=0$ and $z=-h_{0}$ are known. In fact, we usually do not know the true fluxes. Therefore, the overall RMSE (denoted as $e\left(G_{0 j}\right)$ ) of the calculated surface ground heat flux of a particular frequency component $j$ can be larger than $e\left(g_{0}^{*}\right)$. For determining vertical discretization $z_{k}$, after various tests, it is suggested to use the evenly heat-content discretized grid (discretization the vertical profile to have the same heat content within $z_{k}$ and $z_{k+1}$ ) to have the least overall error among our tests for surface ground heat flux simulation.

From Eq. 36, it can be seen that the heat content of a particular frequency component decays exponentially with depth. Of the frequency component, the ratio $p$ of the heat content stored from the surface to the depth $d$ to the total heat content within the ground column can be determined as:

$$
\begin{aligned}
p\left(d^{*}\right) & =\frac{\int_{-d^{*}}^{0}\left\|\tau^{*}\left(z^{*}\right)\right\| \mathrm{d} z^{*}}{\int_{-\infty}^{0}\left\|\tau^{*}\left(z^{*}\right)\right\| \mathrm{d} z^{*}}=\frac{\int_{-d^{*}}^{0} \exp \left(z^{*}\right) \mathrm{d} z^{*}}{\int_{-\infty}^{0} \exp \left(z^{*}\right) \mathrm{d} z^{*}}=\frac{\left.\exp \left(z^{*}\right)\right|_{-d^{*}} ^{0}}{\left.\exp \left(z^{*}\right)\right|_{-\infty} ^{0}} \\
& =1-\exp \left(-d^{*}\right)
\end{aligned}
$$

Reorganizing the above equation, the function $d(p)$ can be determined as:

$d^{*}(p)=-\ln (1-p)$

Based on the above criterion, the vertical discretization $z_{k}$ of a ground column can be determined (denoted as evenly heat-content discretization).

Table 2 lists the values of $z_{k}^{*}, h_{k}^{*}, h_{e k}^{p^{*}}$ and normalized overall error $e\left(G_{0 j}^{*}\right)\left(=e\left(G_{0 j}\right) / \mathrm{g}_{0 j \mathrm{STD}}\right)$ of the evenly heatcontent discretization from single layer $(m=0)$ up to 6 layers $(m=5)$ of a particular frequency component. It is uneven grid with finer discretization near the surface, and infinitely coarse grid for the bottommost layer. The subsurface fluxes $G_{k, n}$ (for $k \geq 1$ ) can be determined as a function of ground temperatures according to the finite difference Eq. 49. Then, the system of $(m+1)$ ordinary differential equations for determining the skin temperature $\left(T_{0}\right)$ as well as ground temperatures $\left(T_{1}, \ldots, T_{\mathrm{m}}\right)$ can be rewritten from Eq. 1 as:

$\left\{\begin{array}{c}\frac{\partial T_{0, n}}{\partial t}=-\frac{G_{0, n}}{\rho_{g} c_{g} h_{e 0}}-\frac{D}{h_{e 0}}\left(\frac{T_{0, n}-T_{1, n}}{z_{0}-z_{1}}\right) \\ \vdots \\ \frac{\partial T_{k, n}}{\partial t}=\frac{D}{h_{e k}}\left(\frac{T_{k-1, n}-T_{k, n}}{z_{k-1}-z_{k}}-\frac{T_{k, n}-T_{k+1, n}}{z_{k}-z_{k+1}}\right) \\ \vdots \\ \frac{\partial T_{m, n}}{\partial t}=-\frac{G_{m, n}}{\rho_{g} c_{g} h_{e m}}=\frac{D}{h_{e m}}\left(\frac{T_{m-1, n}-T_{m, n}}{z_{m-1}-z_{m}}\right)\end{array}\right.$

where the "op" scheme, proposed by this study, sets $h_{e k}=h_{e k}^{p}$ according to Eq. 20, and the "cv" scheme sets 
Table 2 Vertical discretizations of evenly heat-content discretized grids and their normalized overall errors $e\left(G_{0 j}^{*}\right)\left(=e\left(G_{0 j}\right) / g_{0 j \mathrm{STD}}\right)$ of surface ground heat flux of a particular frequency component $j$ when $\partial G_{0}^{*} / \partial T_{0}^{*}=2.64$

\begin{tabular}{|c|c|c|c|c|c|c|}
\hline $\mathrm{m}$ & $p_{k}^{*}(k=0, \ldots, m+1)$ & $z_{k}^{*}(k=0, \ldots, m+1)$ & $h_{k}^{*}(k=0, \ldots, m)$ & $h_{e k}^{p^{*}}(k=0, \ldots, m)$ & $e\left(G_{0 j}^{*}\right)(\%)$ & $e\left(g_{0}^{*}\right)(\%)$ \\
\hline 0 & 0,1 & $0,-\infty$ & $\infty$ & 0.5357 & 67.59 & 68.14 \\
\hline 1 & $0,1 / 2,1$ & $0,-0.6931,-\infty$ & $0.3466, \infty$ & $0.2876,1.0334$ & 14.25 & 4.80 \\
\hline 2 & $0,1 / 3,2 / 3,1$ & $0,-0.4005,-1.1087,-\infty$ & $0.2002,0.5543, \infty$ & $0.1803,0.5128,1.0426$ & 4.75 & 1.48 \\
\hline 3 & $0,1 / 4,2 / 4,3 / 4,1$ & $\begin{array}{c}0,-0.2877,-0.6931 \\
\quad-1.3863,-\infty\end{array}$ & $\begin{array}{l}0.1438,0.3466 \\
\quad 0.5493, \infty\end{array}$ & $\begin{array}{r}0.1335,0.3365 \\
0.5108,1.0334\end{array}$ & 2.05 & 0.69 \\
\hline 4 & $\begin{array}{l}0,1 / 5,2 / 5,3 / 5 \\
\quad 4 / 5,1\end{array}$ & $\begin{array}{l}0,-0.2231,-0.5108,-0.9163 \\
\quad-1.6094,-\infty\end{array}$ & $\begin{array}{l}0.1116,0.2554, \\
\quad 0.3466,0.5493, \infty\end{array}$ & $\begin{array}{l}0.1054,0.2513,0.3365 \\
\quad 0.5108,1.0334\end{array}$ & 1.09 & 0.37 \\
\hline 5 & $\begin{array}{l}0,1 / 6,2 / 6,3 / 6 \\
\quad 4 / 6,5 / 6,1\end{array}$ & $\begin{array}{c}0,-0.1823,-0.4055,-0.6931 \\
\quad-1.0986,-1.7918,-\infty\end{array}$ & $\begin{array}{l}0.0912,0.2027,0.2554 \\
0.3466,0.5493, \infty\end{array}$ & $\begin{array}{l}0.0870,0.2007,0.2513 \\
0.3365,0.5108,1.0334\end{array}$ & 0.71 & 0.22 \\
\hline
\end{tabular}

In addition, the corresponding normalized error $e\left(g_{0}^{*}\right)$ of surface ground heat flux from the skin layer, of which the subsurface flux at $z=-h_{0}$ is prescribed, is listed for comparison

$h_{e k}=h_{k}$. The normalized overall error $e\left(G_{0 j}^{*}\right)$ in the table is determined by solving the above ordinary-differentialequation system by the Runge-Kutta method using the software Mathematica (http://www.wolfram.com) by setting $\partial G_{0}^{*} / \partial T_{0}^{*}$ at 2.64. It can be seen that $e\left(G_{0 j}^{*}\right)$ reduces from $68 \%$ of the single-layer discretization $(m=0)$ to $2 \%$ of the 4-layer discretization ( $m=3$ ). Thus, the more the layers, the lower the overall error is. The effective thickness in each layer is thinner than its respective physical thickness, especially for the bottommost-numerical layer. Comparing to the normalized error $e\left(g_{0}^{*}\right)$ of the skin layer, the normalized overall error $e\left(G_{0 j}^{*}\right)$ for $m$ in the range of $1-5$ is a factor of 3 larger than that of $e\left(g_{0}^{*}\right)$ for the same $h_{0}$. This is reasonable since the error in subsurface flux $\left(z=-h_{0}\right)$ is not included in $e\left(g_{0}^{*}\right)$. A tri-diagonal matrix for solving the temperatures by the "op" scheme is illustrated in the Appendix (See Appendix 4 for details), which can be solved directly without any iteration by numerical solvers (e.g., Press et al. 1992).

Figure 4 shows the optimal effective thicknesses $h_{e 0}^{p *}$ of various $\partial G_{0}^{*} / \partial T_{0}^{*}(0,1,2,4, \infty), h_{0}^{*}$ and $h_{a 0}^{*}$ as functions of $h_{0}^{*}$. It shows that when $h_{0}^{*}>0.6$, the value of $h_{e 0}^{p^{*}}$ is scattered and decreased with $\partial G_{0}^{*} / \partial T_{0}^{*}$. But when $h_{0}^{*}<0.6$, the value of $h_{e 0}^{p^{*}}$ is almost independent to $\partial G_{0}^{*} / \partial T_{0}^{*}$. For example, when $h_{0}^{*}=d^{*}(25 \%)=0.144, h_{e 0}^{p^{*}}$ is within [0.133530, 0.133533], changing very little with $\partial G_{0}^{*} / \partial T_{0}^{*}$ (bottom panel of the Fig. 4). From Table 2, it can be seen $h_{0}^{*}<0.35$ for the evenly heat-content discretization with layers $\geq 2$ (or $m \geq 1$ ). Therefore, it is suggested to determine $h_{e 0}^{p^{*}}$ using some typical values of $\partial G_{0}^{*} / \partial T_{0}^{*}$, such as the annual median value of 2.64 of the Bondville site (shown in the later section) when the value of $\partial G_{0}^{*} / \partial T_{0}^{*}$ is not immediately available.

\section{Vertical discretization for multiple frequency components}

Table 2 shows the vertical discretizations of evenly heatcontent discretized grids for a particular frequency
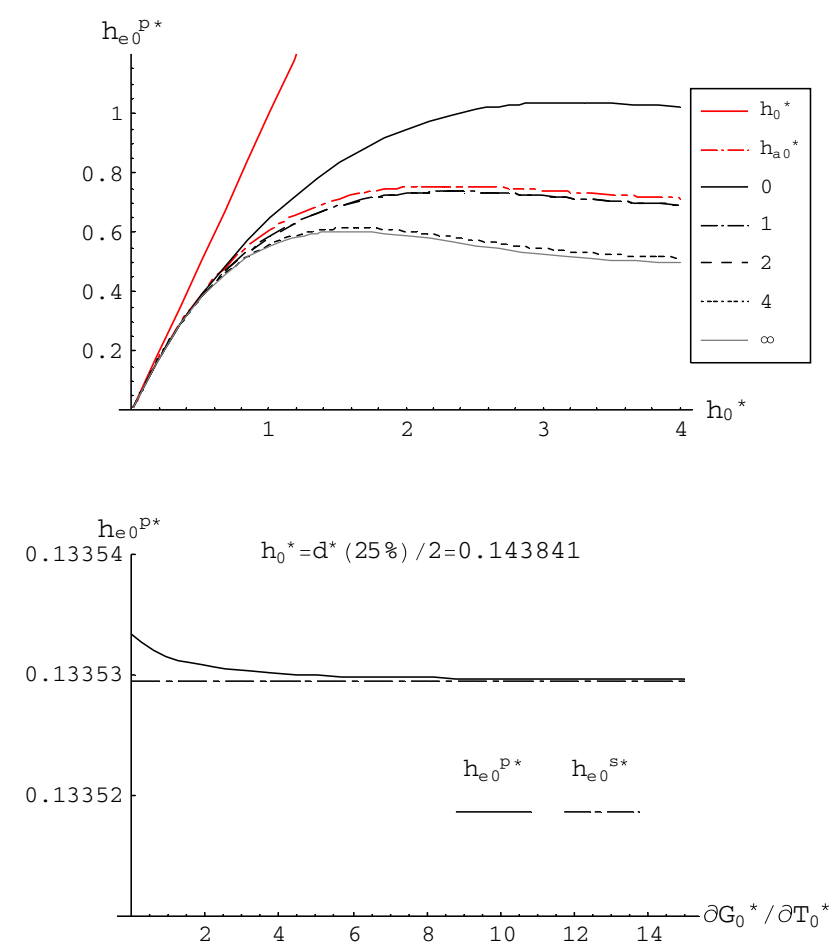

Fig. 4 Top panel optimal effective thicknesses $h_{e 0}^{p^{*}}$ of various $\partial G_{0}^{*} /$ $\partial T_{0}^{*}$ and $h_{a 0}^{*}$ as functions of the skin-layer thickness $h_{0}^{*}$, where the numbers in the legend denote the values of $\partial G_{0}^{*} / \partial T_{0}^{*}$; bottom panel $h_{e 0}^{p^{*}}$ as a function of $\partial G_{0}^{*} / \partial T_{0}^{*}$ for $h_{0}^{*}=d^{*}(25 \%)=0.14381$. All the variables are expressed in dimensionless units. Please see Eq. 52 for the definitions

component. Nonetheless, there are uncertainties with the frequency chosen. In fact, diurnal, annual and many other frequency components are present in ST. In the followings, we use the subscripts " $d ", " y "$ and "s" denoting the properties of "diurnal", "annual" and "sun-spot" frequency components, respectively. Besides, it is well known that in the deep ground, the dominant frequency component usually is much slower than in the surface (Huang et al. 2000). Hence, the dominant frequency component of the 
bottommost-numerical layer can be slower than the diurnal frequency. Therefore, the locations $z_{k}$ of a ground column should be chosen to be able to record the temperature evolutions of multiple dominant frequency components. This section uses the skin temperature data at a cropland site, Bondville, IL, USA $\left(40.01^{\circ} \mathrm{N}, 88.29^{\circ} \mathrm{W}\right)$ to design a better discretization for multiple frequency components.

At the Bondville site, the soil is silt loam. The heat diffusivity $D$ for the soil with water content within wilting point and field capacity is $6.2 \times 10^{-7} \mathrm{~m}^{2} \mathrm{~s}^{-1}$ and its volume heat capacity $\rho_{g} c_{g}$ is about $2.4 \times 10^{6} \mathrm{~J} \mathrm{~m}^{-3} \mathrm{~K}^{-1}$ (de Vries 1975). A more detailed description of the site can be found in Meyers and Hollinger (2004) and Tsuang (2005). Figure 5 shows the time series of the observed ST at the cropland site from 1997 to 2000, and its frequency spectrum. It can be seen that its major frequency components include $1 / y, 1 / d, 1 / 12 h, 1 / 8 h$ and $1 / 6 h$. It can be fitted by cosine functions. The result after truncating terms with $\Delta T_{0} \leq 1 \mathrm{~K}$ or $\Delta g_{0} \leq 1 \mathrm{~W} \mathrm{~m}^{-2}$ is as:

$$
\begin{aligned}
T_{0}(t)= & 285.15-1.14 \cos \left(\frac{2 \pi}{4 \mathrm{y}} t\right) \\
& +11.88 \cos \left(\frac{2 \pi}{1 \mathrm{y}}(t-199 d)\right) \\
& +3.44 \cos \left(\frac{2 \pi}{1 d}(t-14 h)\right) \\
& +0.94 \cos \left(\frac{4 \pi}{1 d}(t-1 h)\right) \\
& +0.25 \cos \left(\frac{6 \pi}{1 d}(t-5 h)\right) \\
& +0.10 \cos \left(\frac{8 \pi}{1 d}(t-3 h)\right)
\end{aligned}
$$

where $t$ is time starting from 0:00 LT, 1 January 1997 and the unit of the ST is in K. Three dominant frequency components are identified. Their frequencies are $1 / d, 1 / y$ and $1 / 4 y$. The analytical solutions of their corresponding temperature profiles and ground heat fluxes of the ST (Eq. 28) observed at the site can be determined from Eqs. 36 and 38, directly. A comparison between observed monthly ground heat flux with the analytical solution can be found in Tsuang (2005). It shows that the correlation coefficient is 0.8 with RMSE at $5.6 \mathrm{~W} \mathrm{~m}^{-2}$. Table 3 shows the STDs of ST and $G_{0}$ of each frequency component. It can be seen that the STD of $G_{0}$ of the diurnal frequency component is the largest among all the frequency components although it's STD of ST is less than the annual frequency component. Therefore, calculating the optimal $h_{e 0}$ based on the diurnal frequency component is a proper choice.

Solar radiation is the dominant surface energy component for heating Earth's surface (Tsuang 2003) and solar
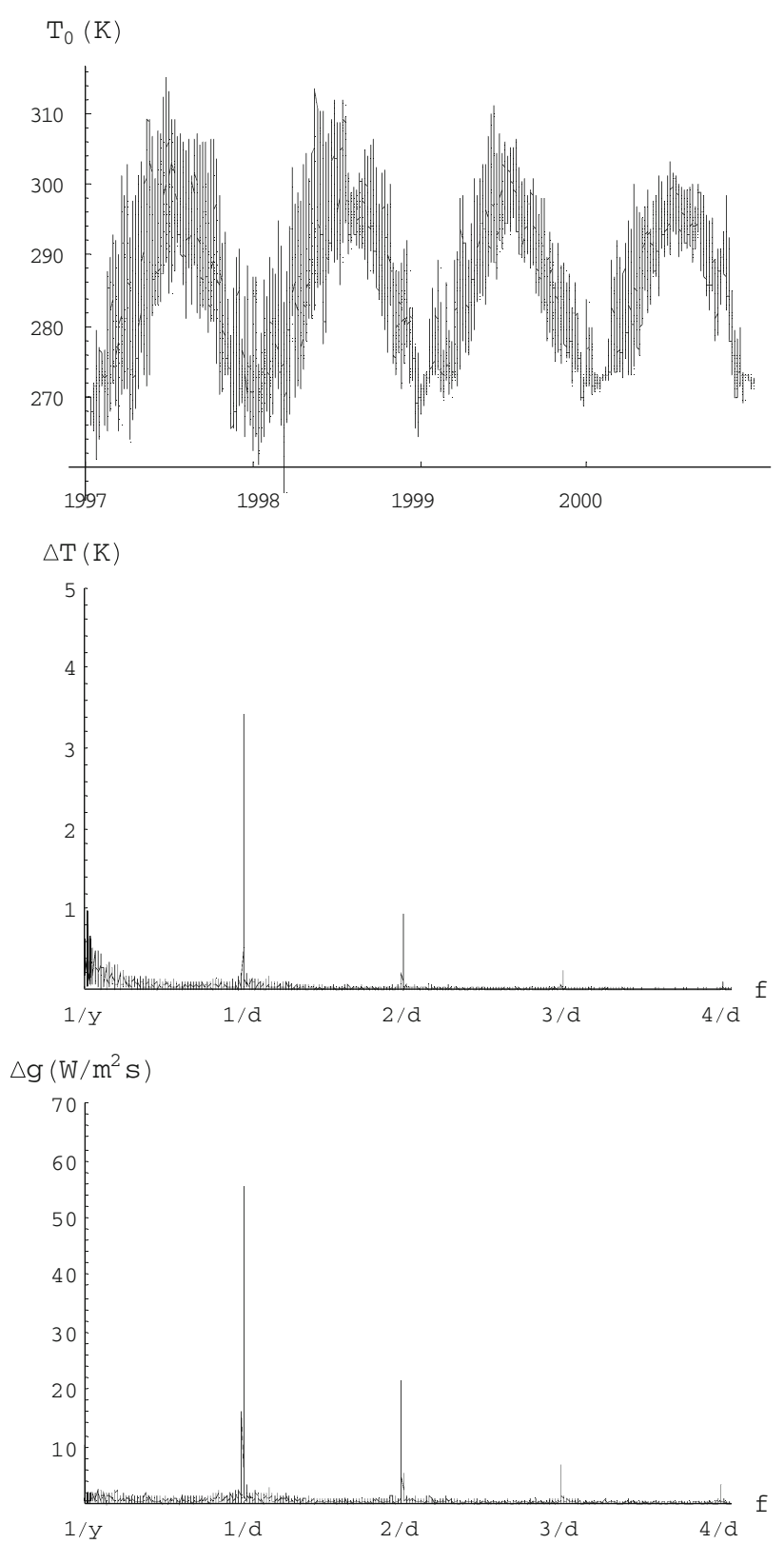

Fig. 5 Top skin temperature $\left(T_{0}\right)$ observed at a cropland site, Bondville, IL, USA $\left(40.01^{\circ} \mathrm{N}, 88.29^{\circ} \mathrm{W}\right)$ from $1997-2000$, middle the amplitudes $\Delta T$ of skin temperature, and bottom the amplitudes $\Delta g$ of surface ground heat flux of various frequency components

radiation has strong diurnal and annual cycles. In addition, the sun-spot cycle of 11 years might be of interest for climate study. The variation caused by the sunspot cycle to solar output is on the order of $0.1 \%$ of the solar constant (a peak-to-trough range of $1.3 \mathrm{~W} \mathrm{~m}^{-2}$ compared to $1,366 \mathrm{~W} \mathrm{~m}^{-2}$ for the average solar constant) (Ramaswamy et al. 2001). This range is slightly smaller than the change in radiative forcing caused by the increase in atmospheric $\mathrm{CO}_{2}$ since the eighteenth century. 
Table 3 Characteristics of the dominant frequency components of the skin temperature observed at the Bondville site (except for $j=7$ ) during $1997-2000$

\begin{tabular}{|c|c|c|c|c|c|c|c|}
\hline$j$ & Freq. & $\omega_{\mathrm{j}}(1 / \mathrm{s})$ & $\Delta T_{\mathrm{j}}(\mathrm{K})$ & $\tau_{\mathrm{jSTD}}(\mathrm{K})$ & $\Delta g_{\mathrm{j}}\left(\mathrm{W} \mathrm{m}^{-2}\right)$ & $g_{\text {jSTD }}\left(\mathrm{W} \mathrm{m}^{-2}\right)$ & $\sqrt{2 D / \omega_{j}}(\mathrm{~m})$ \\
\hline 1 & $4 / d$ & 2.91E-04 & 0.10 & 0.07 & 3.22 & 2.28 & 0.07 \\
\hline 2 & $3 / d$ & $2.18 \mathrm{E}-04$ & 0.25 & 0.18 & 6.98 & 4.93 & 0.08 \\
\hline 3 & $2 / d$ & $1.45 \mathrm{E}-04$ & 0.94 & 0.66 & 21.42 & 15.15 & 0.09 \\
\hline 4 & $1 / d$ & 7.27E-05 & 3.44 & 2.43 & 55.44 & 39.20 & 0.13 \\
\hline 5 & $1 / y$ & $1.99 \mathrm{E}-07$ & 11.88 & 8.40 & 10.02 & 7.08 & 2.50 \\
\hline 6 & $1 / 4 y$ & 4.98E-08 & 1.14 & 0.81 & 0.48 & 0.34 & 4.99 \\
\hline 7 & $1 / 11 y$ & $1.81 \mathrm{E}-08$ & 2.56 & 1.81 & 0.65 & 0.46 & 8.28 \\
\hline$T_{0 \mathrm{STD}}$ or $G_{0 \mathrm{STD}}$ & & & & 8.97 & & 39.84 & \\
\hline
\end{tabular}

At the Bondville cropland site, from Table 3, the STD of $G_{0}$ of the diurnal component was $39 \mathrm{~W} \mathrm{~m}^{-2}$, and that of the annual frequency component was $7 \mathrm{~W} \mathrm{~m}^{-2}$. To have an accuracy at $1 \mathrm{~W} \mathrm{~m}^{-2}$, the level index " $m$ " should be equal to or larger than 3 for the diurnal frequency component, and 2 for the annual frequency component according to Table 2. In respect to the sun-spot frequency component there is no need to reserve layers for the component since its STD of $G_{0}$ was $0.46 \mathrm{~W} \mathrm{~m}^{-2}$, which is only half of $1 \mathrm{~W} \mathrm{~m}^{-2}$. If we choose $m=3$ for the diurnal component, $m=2$ for the annual component and $m=0$ for the sun-spot component (denoted as the "op $(3,2,0)$ " scheme), then, the overall error can be roughly estimated as:
Hence, $e\left(G_{0}\right)$ of "op $(3,2,0)$ " can be approximated as the above Eq. 29.

Table 4 lists the grid structures and effective thicknesses of "op(3,2,0)" and others (such as "A74", "D78", "ECHAM"). The vertical coordinates $\left(z_{k}\right)$ of the 5 layers of "op $(3,2,0)$ " are at 25,50 and $75 \%$ of the heat storage of the diurnal component, and 33 and $67 \%$ of the annual component. That is, they are at $-d^{*}(0.25) \sqrt{2 \mathrm{D} / \omega_{\mathrm{d}}},-d^{*}$ $(0.5) \sqrt{2 \mathrm{D} / \omega_{\mathrm{d}}},-d^{*}(0.75) \sqrt{2 \mathrm{D} / \omega_{\mathrm{d}}},-d^{*}(0.33) \sqrt{2 \mathrm{D} / \omega_{\mathrm{y}}}$ and $-d^{*}(0.67) \sqrt{2 \mathrm{D} / \omega_{\mathrm{y}}}$, respectively; or $-0.038,-0.090$, $-0.181,-1.012$, and $-2.742 \mathrm{~m}$, respectively, for the heat

$$
\begin{aligned}
e\left(G_{0}\right) & =\sqrt{\sum_{j}\left(e\left(G_{0 j}^{*}\right) g_{0 j \mathrm{STD}}\right)^{2}} \approx \sqrt{\left(e\left(G_{0}^{p *}(m=3)\right) g_{0 d \mathrm{STD}}\right)^{2}+\left(e\left(G_{0}^{p *}(m=2)\right) g_{0 y \mathrm{STD}}\right)^{2}+\left(e\left(G_{0}^{n *}(m=0)\right) g_{0 s \mathrm{STD}}\right)^{2}} \\
& =\sqrt{(0.020 \times 39.2)^{2}+(0.048 \times 7.08)^{2}+(1 \times 0.46)^{2}}=1.09 \mathrm{Wm}^{-2}
\end{aligned}
$$

where $e\left(G_{0}^{p^{*}}\right)$ and $e\left(G_{0}^{n^{*}}\right)$ denote the normalized overall errors of surface ground heat flux simulation of the "op" scheme and the no-heat-capacity scheme ("nh"), respectively. Note that the value of $e\left(G_{0 j}^{n^{*}}\right)$ is 1 for the single-layer $\left(m=0, h_{0}^{*} \rightarrow \infty\right)$ "nh" scheme, of which $e\left(G_{0 j}^{*}\right)$ can be determined by setting $h_{e 0}^{*}=0$ and $h_{0}^{*} \rightarrow \infty$ into Eq. 24 . Note that for the single layer scheme $e\left(G_{0 j}^{*}\right)=e\left(g_{0}^{*}\right)$ since the subsurface ground heat flux at $z=-h_{0}(\rightarrow-\infty)$ is known $(=0)$. For the "op $(3,2,0)$ " scheme, since there is no middle layer recording the temperature evolution of the sun-spot frequency component, $h_{0 s}^{*}$ of the sun-spot frequency component approaches infinity. Therefore, the effective thickness $h_{e 0 s}^{*}$ of the sun-spot cycle is close to 0 comparing to $h_{0 s}^{*}$. $\left(h_{e 0 s}^{*}=h_{e 0 d}^{p *} \sqrt{2 D / \omega_{d}} / \sqrt{2 D / \omega_{s}}=\right.$ $0.000275)$. Therefore, the accuracy of the sun-spot frequency component is close to that of " $\mathrm{nh}$ " for $h_{0}^{*} \rightarrow \infty$. diffusivity $D$ of $6.2 \times 10^{-7} \mathrm{~m}^{2} \mathrm{~s}^{-1}$ (silt loam). Then, $h_{e 0}$ is determined to be $0.017 \mathrm{~m}$ by minimizing the error of the diurnal frequency component when $\partial G_{0} / \partial T_{0}=$ $42 \mathrm{~W} \mathrm{~m}^{-2} \mathrm{~K}^{-1}$ (the annual median value of a cropland site in Bondville, USA, shown in the later section), and $h_{e m}$ to be $2.579 \mathrm{~m}$ by minimizing the error of the annual frequency component.

\section{Case study—a cropland site}

The above section estimates that "op(3,2,0)" can simulate surface ground heat flux with an accuracy at about $1 \mathrm{~W} \mathrm{~m}^{-2}$. This section applies the above discretization for determining skin temperature at a cropland site, Bondville, IL, USA $\left(40.01^{\circ} \mathrm{N}, 88.29^{\circ} \mathrm{W}\right)$, for a case study. Seven cases 
Table 4 Vertical discretization of various schemes for heat diffusivity at $6.2 \times 10^{-7} \mathrm{~m}^{2} \mathrm{~s}^{-1}$, when $\partial G_{0} / \partial T_{0}$ is fixed at $42 \mathrm{~W} \mathrm{~m}^{-2} \mathrm{~K}^{-1}$ (the annual median value of a cropland site in Bondville, USA)

\begin{tabular}{|c|c|c|c|c|c|}
\hline Abbr & $\begin{array}{l}\text { Levels } \\
(m+1)\end{array}$ & $z_{k}(k=0, \ldots, m+1)(\mathrm{m})$ & $h_{k}(k=0, \ldots, m)(\mathrm{m})$ & $h_{e k}^{p}(k=0, \ldots, m)(\mathrm{m})$ & Ref. \\
\hline A74 & 1 & $0,-\infty$ & $\infty$ & 0.0923 & Arakawa and Mintz (1974) \\
\hline D78 & 1 & $0,-\infty$ & $\infty$ & 0.1305 & Deardorff (1978) \\
\hline $\mathrm{op}(0,0,0)$ & 1 & $0,-\infty$ & $\infty$ & 0.0701 & $\begin{array}{l}\text { Optimal 1-level } \\
\text { discretization (this study) }\end{array}$ \\
\hline $\operatorname{op}(1,0,0)$ & 2 & $0,-0.0905,-\infty$ & $0.0452, \infty$ & $0.0376,0.1349$ & $\begin{array}{l}\text { Optimal 2-level } \\
\text { discretization (this study) }\end{array}$ \\
\hline$o p(1,1,0)$ & 3 & $0,-0.0905,-1.7298,-\infty$ & $0.0452,0.8196, \infty$ & $0.0376,0.1341,2.5213$ & $\begin{array}{l}\text { Optimal 3-level } \\
\text { discretization (this study) }\end{array}$ \\
\hline$o p(2,1,0)$ & 4 & $\begin{aligned} 0, & -0.0529,-0.1434 \\
& -1.7298,-\infty\end{aligned}$ & $\begin{array}{l}0.0268,0.0452 \\
0.8384, \infty\end{array}$ & $\begin{array}{l}0.0238,0.0667,0.1340 \\
\quad 2.4862\end{array}$ & $\begin{array}{l}\text { Optimal 4-level } \\
\text { discretization (this study) }\end{array}$ \\
\hline echam & 5 & $\begin{array}{c}-0.0325,-0.192,-0.7755 \\
-2.683,-6.984,-\infty\end{array}$ & $\begin{array}{l}0.065,0.254,0.913 \\
\quad 2.902,5.7\end{array}$ & $=h_{k}$ & Roeckner et al. (2003) \\
\hline ecmwf & 5 & $\begin{array}{l}0,-0.035,-0.175,-0.64 \\
\quad-1.945,-\infty\end{array}$ & $0.07,0.21,0.72,1.89$ & $0,0.07,0.21,0.72,1.89$ & Viterbo and Beljaars (1995) \\
\hline $\operatorname{cv}(3,2,0)$ & 5 & $\begin{array}{l}-0.0376,-0.0905,-0.1810 \\
-1.0119,-2.7417,-\infty\end{array}$ & $\begin{array}{l}0.0640,0.0717 \\
\quad 0.4607,1.2803, \infty\end{array}$ & $=h_{k}$ & This study \\
\hline op $(3,1,0)$ & 5 & $\begin{aligned} 0, & -0.0376,-0.0905,-0.1810 \\
& -1.7298,-\infty\end{aligned}$ & $\begin{array}{l}0.0188,0.0265 \\
\quad 0.0717,0.8196, \infty\end{array}$ & $\begin{array}{l}0.0174,0.0439,0.0667 \\
0.1339,2.4605\end{array}$ & $\begin{array}{l}\text { Optimal 5-level } \\
\quad \text { discretization (this study) }\end{array}$ \\
\hline$o p(3,2,0)$ & 6 & $\begin{array}{l}0,-0.0376,-0.0905,-0.1810 \\
\quad-1.0119,-2.7417,-\infty\end{array}$ & $\begin{array}{l}0.0188,0.0452 \\
0.0717,0.4607 \\
1.2803, \infty\end{array}$ & $\begin{array}{l}0.0174,0.0439,0.0667 \\
0.1378,1.1677 \\
2.5789\end{array}$ & $\begin{array}{l}\text { Optimal 6-level } \\
\text { discretization (this study) }\end{array}$ \\
\hline$o p(3,2,1)$ & 7 & $\begin{array}{l}0,-0.0376,-0.0905,-0.1810 \\
\quad-1.0119,-2.7417,-5.7371 \\
\quad-\infty\end{array}$ & $\begin{array}{l}0.0188,0.0452 \\
\quad 0.0717,0.4607 \\
1.2803,2.3626, \infty\end{array}$ & $\begin{array}{l}0.0174,0.0439,0.0667 \\
0.1378,1.1677 \\
2.0827,6.3753\end{array}$ & This study \\
\hline
\end{tabular}

Here, "levels" denotes the number of equations for temperatures (including the skin temperature)

of cascade frequency components based on the frequency component data observed at this study site are used to construct the cases (Table 5).

Figure 6 shows the time series of observed $\partial G_{0} / \partial T_{0}$ at a cropland site, Bondville, IL, USA $\left(40.01^{\circ} \mathrm{N}, 88.29^{\circ} \mathrm{W}\right)$ in 2000. In addition, $\partial G_{0}{ }^{*} / \partial T_{0}^{*}$ of the diurnal frequency component is also shown in the figure. At the site, the daytime aerodynamic and canopy resistances in the summer are about 37 and $60 \mathrm{~s} \mathrm{~m}^{-1}$, respectively (Wilson et al.

Table 5 Analytical skin temperature used for case studies

\begin{tabular}{lll}
\hline Case & $T_{0}(t)(\mathrm{K})$ & Freq. comp. \\
\hline 1 & $285.15+3.44 \cos \left(\frac{2 \pi}{1 d}(t-14 h)\right)$ & $1 / d$ \\
2 & case $1+0.94 \cos \left(\frac{4 \pi}{1 d}(t-1 h)\right)$ & Case $1+2 / d$ \\
3 & case $2+0.25 \cos \left(\frac{6 \pi}{1 d}(t-5 h)\right)$ & Case $2+3 / d$ \\
4 & case $3+0.10 \cos \left(\frac{8 \pi}{1 d}(t-3 h)\right)$ & Case $3+4 / d$ \\
5 & case $4+11.88 \cos \left(\frac{2 \pi}{1 y}(t-199 d)\right)$ & Case $4+1 / y$ \\
6 & case $5-1.14 \cos \left(\frac{2 \pi}{4 y} t\right)$ & Case $5+1 / 4 y$ \\
7 & case $6+2.56 \cos \left(\frac{2 \pi}{11 y} t\right)$ & Case $6+1 / 11 y$ \\
\hline
\end{tabular}

2002). Following the method of Wilson et al. (2002), $r_{a}$ is derived from the sum of the resistance to momentum transport and an excess resistance for scalar fluxes (Verma et al. 1986) and $r_{c}$ is determined according to the PenmanMonteith approximation to the big leaf equations (Jarvis and McNaughton 1986; Shuttleworth et al. 1984). It can be seen that at this site, typical value for winter nighttime $\partial G_{0}^{*} / \partial T_{0}^{*}\left(\partial G_{0} / \partial T_{0}\right)$ was about $1.8\left(29.04 \mathrm{~W} \mathrm{~m}^{-2} \mathrm{~K}^{-1}\right)$, and that of summer day was about $4.4\left(70.93 \mathrm{~W} \mathrm{~m}^{-2} \mathrm{~K}^{-1}\right)$, of which the annual mean was $2.86\left(46 \mathrm{~W} \mathrm{~m}^{-2} \mathrm{~K}^{-1}\right)$ with the median value at $2.64\left(42 \mathrm{~W} \mathrm{~m}^{-2} \mathrm{~K}^{-1}\right)$, when $T_{0}$ during wintertime (November-January) was usually $<273 \mathrm{~K}$.

Table 6 shows the bias, RMSE and normalized RMSE of skin temperature, and the bias, RMSE and normalized RMSE for surface ground heat of Case 7 simulated by “A74”, “D78”, “op(0,0,0)”, “op $(1,0,0)$ ”, “op $(1,1,0)$, “op(2,1,0)", “echam”, “ecmwf”, “ecmwf + op”, “cv $(3,2,0)$ ", “op(3,1,0)", "echam + op", “cv(3,2,0) + nh", "cv(3,2,0) + op", “op(3,2,0)" and "op(3,2,1)" by solving Eq. 27 by the Runge-Kutta method. Figure 7 illustrates the time series and the spectrums of calculated skin temperature $T_{0, n}$ and surface ground heat flux $G_{0, n}$ among "A74", "echam", " $\operatorname{cv}(3,2,0)$ " and "op(3,2,0)" for Case 7 . Here, the 
Fig. 6 Time series of observed $\partial G_{0} / \partial T_{0}$ and hourly composite values at a cropland site, Bondville, IL, USA $\left(40.01^{\circ} \mathrm{N}\right.$, $88.29^{\circ} \mathrm{W}$ ) in 2000 , where $\partial G_{0}^{*} /$ $\partial T_{0}^{*}$ is making nondimensional by the diurnal frequency component. The midday period is from 10 to $14 \mathrm{LT}$ and the midnight period is from 22 to 02 LT. Summer period is defined from June to August and winter period is defined from November to January
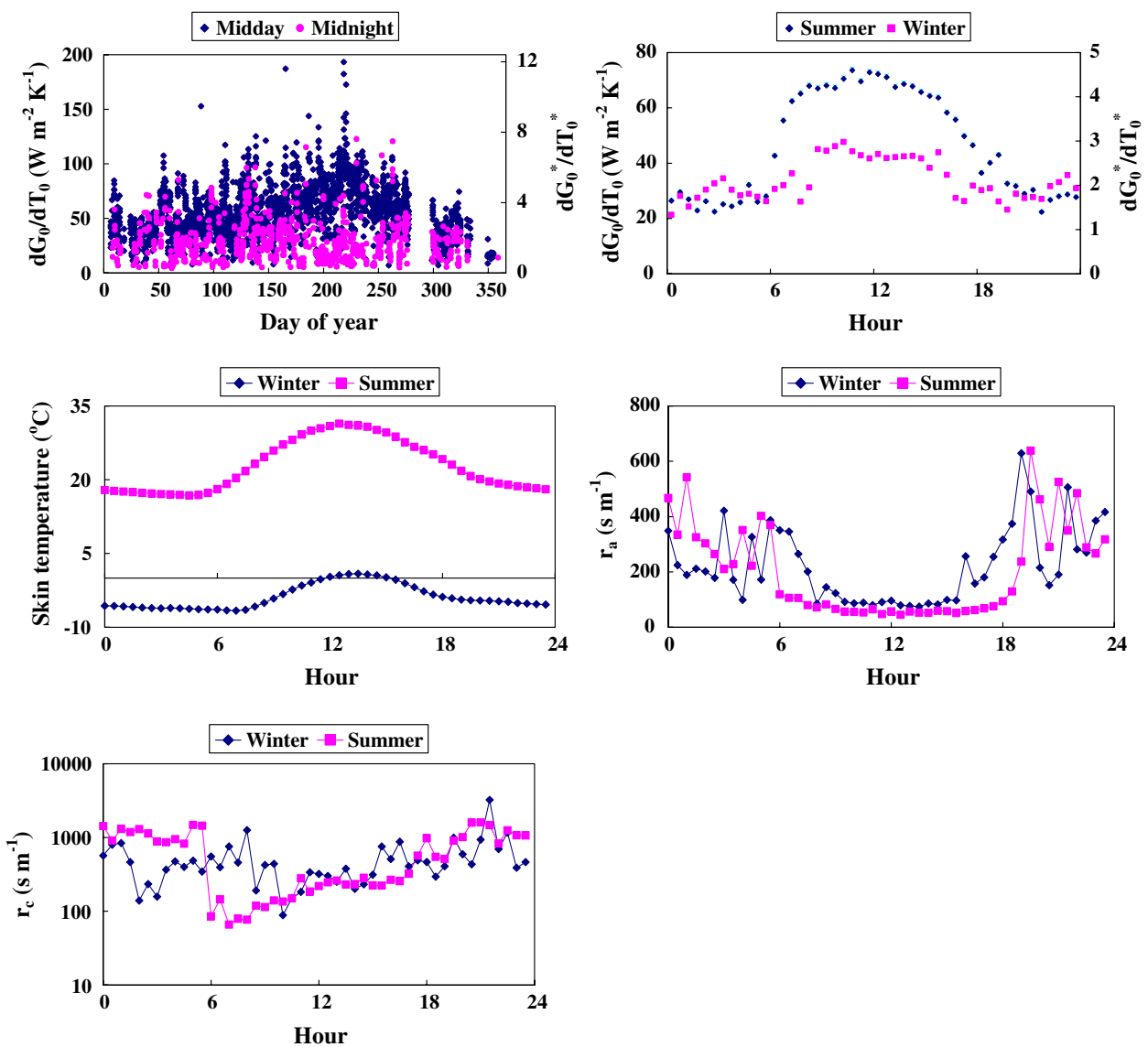

parentheses $(d, y, s)$ denotes the number " $m$ " (Table 2) of evenly heat-content discretized layers used for recording the diurnal temperature profile $(d)$, the annual profile $(y)$ and the sun-spot frequency profile (11 y) (s), respectively. The same initial condition $\left(T\left(z_{k}, 0\right)\right)$ and the same boundary conditions $(G(0, t), G(-\infty, t))$ are used for all the calculations. The conditions are prescribed as those of their corresponding analytical forms (Eqs. 36 and 37). The numerical results are compared with the analytical $T_{0}$ of Eq. 28 and the analytical $G_{0}$ (Eq. 39). The "cv + nh" scheme denotes using the "cv" scheme for the middle layers, but using the "nh" scheme for the skin layer; similarly, the "cv + op" scheme denotes using the "cv" scheme for the middle layers, but using the "op" scheme for the skin layer.

For Case 7, it can be seen that the normalized overall error of the simulated $G_{0}$ by "op(3,2,0)" is $0.89 \mathrm{~W} \mathrm{~m}^{-2}$, which is close to the value $1.09 \mathrm{~W} \mathrm{~m}^{-2}$ roughly estimated from Eq. 29. This shows the error can be approximated as Eq. 29. For Case 7, it can be seen that the normalized overall errors of the simulated $G_{0}$ by "op $(3,2,0)$ " and "op $(3,2,1)$ " are the lowest group. They are at $2 \%$, or at $0.9 \mathrm{~W} \mathrm{~m}^{-2}$. Those by "A74", "D78" and "op $(0,0,0)$ " are the highest group, varying from 70 to $90 \%$, or within $30-39 \mathrm{~W} \mathrm{~m}^{-2}$; it is expected since there is only one layer $(m=0)$ in these schemes. In addition, it can be seen that for the same vertical structure $(3,2,0)$, "op" is better than "cv + op", "cv + op" is better than "cv $+\mathrm{nh}$ ", and " $\mathrm{cv}+\mathrm{nh}$ " is better than "cv". For Case 7, $e\left(G_{0}^{*}\right)$ of "op $(3,2,0)$ " is at $2 \%$, that of " $\operatorname{cv}(3,2,0)+$ op" $7 \%$, that of " $\operatorname{cv}(3,2,0)+\mathrm{nh} " 12 \%$, and that of " $\operatorname{cv}(3,2,0) " 28 \%$. This shows that using the optimal effective thickness (determined by Eq. 20) for each numerical layer does improve the model system for surface ground heat flux simulation, by more than an order comparing to the conventional finite difference scheme, and by about 6 times comparing to the no-heat capacity scheme used in some state-of-the-art models.

In addition, the difference between simulated results and the analytical solutions are expressed in the frequency spectrum in Fig. 8. It can be seen that the errors simulated by "op $(3,2,0)$ " have been reduced for the component with frequency of the diurnal cycle or higher comparing to "A74", "echam" and "cv( $3,2,0)$ ".

\section{Discussion}

6.1 Multiple frequency components

In respect to frequency components, Table 7 shows the normalized overall errors $e\left(G_{0}^{*}\right)$ of the 7 cases simulated by 


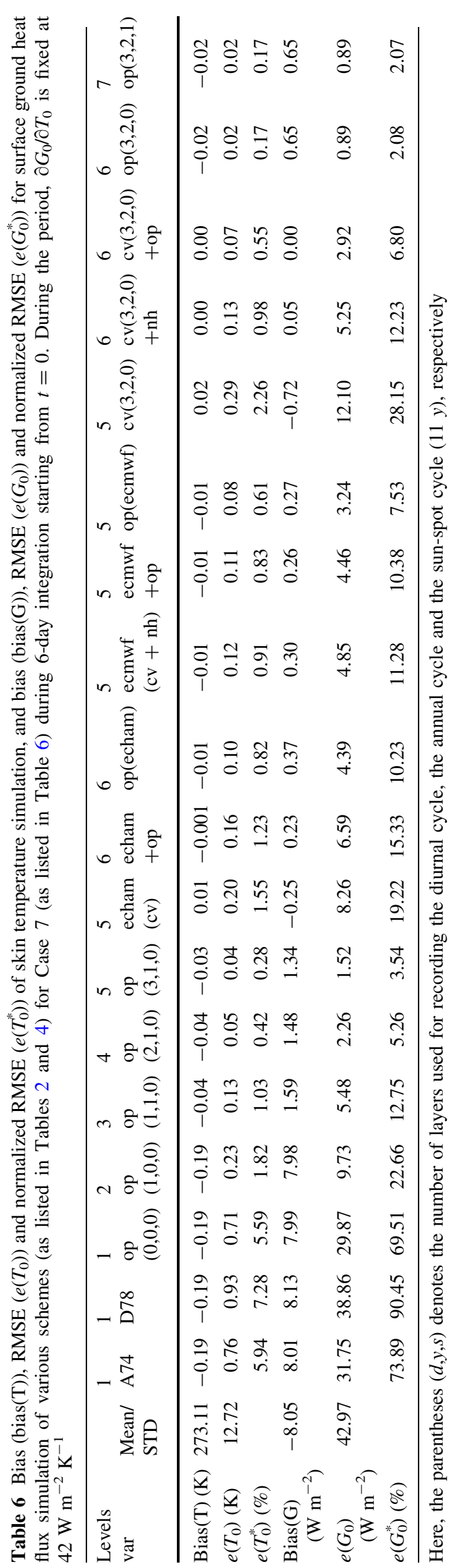
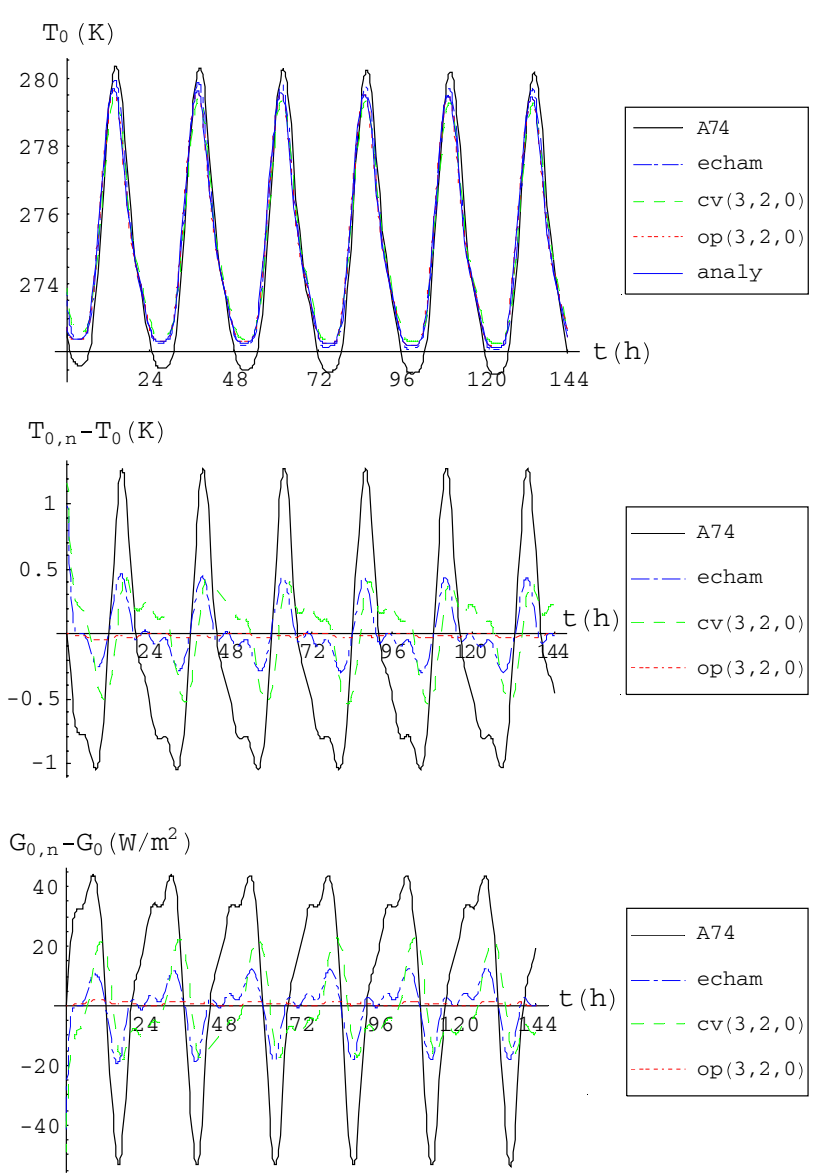

Fig. 7 Time series of calculated skin temperature $T_{0, \mathrm{n}}$ and surface ground heat flux $G_{0, \mathrm{n}}$ among "A74", "echam", "cv(3,2,0)" and "op $(3,2,0)$ " for Case 7 , with frequency components observed at the Bondville cropland site. The vertical discretizations of the schemes are listed in Table 4. Same initial $(T(z, 0))$ and boundary $(G(0, t))$ conditions with zero-heat flux at the bottom boundary layer are used for all the calculations, where $T(z, 0)$ and $G(0, t)$ are prescribed as those of their corresponding analytical forms (Eqs. 36 and 39). The results are compared with the analytical $T_{0}$ of Eq. 28 and its corresponding analytical $G_{0}$ (Eq. 39)

“op(0,0,0)”, “op(1,0,0)”, “op(2,0,0)”, “op(3,0,0)”, “ор $(4,0,0)$ ”, “op(5,0,0)”, “op( $1,1,0)$ ”, “op( $2,1,0)$ ”, “op $(3,1,0)$ ”, "op(3,2,0)" and "op(3,2,1)". Cases 1-4 have diurnal and higher frequency components, but no annual frequency component. Cases 5-7 contain diurnal as well as annual frequency components. In the table, for Cases 1-4, the sequence of the values of $e\left(G_{0}^{*}\right)$ from low to high is "op(5,0,0)" < “op(4,0,0)" < “op(3,0,0)" < "op(2,0,0)" < "op $(1,0,0)$ " < "op $(0,0,0)$ ". It shows that the more layers of $z_{k}$ for keeping tracks the diurnal temperature profile are, its accuracy for calculating $G_{0}$ of the frequency component becomes higher. Nonetheless, although "op $(5,0,0)$ " can calculate $G_{0}$ of the diurnal frequency component accurately, it is not able to handle $G_{0}$ of the annual (or lower) frequency component. The normalized overall errors $e\left(G_{0}^{*}\right)$ 

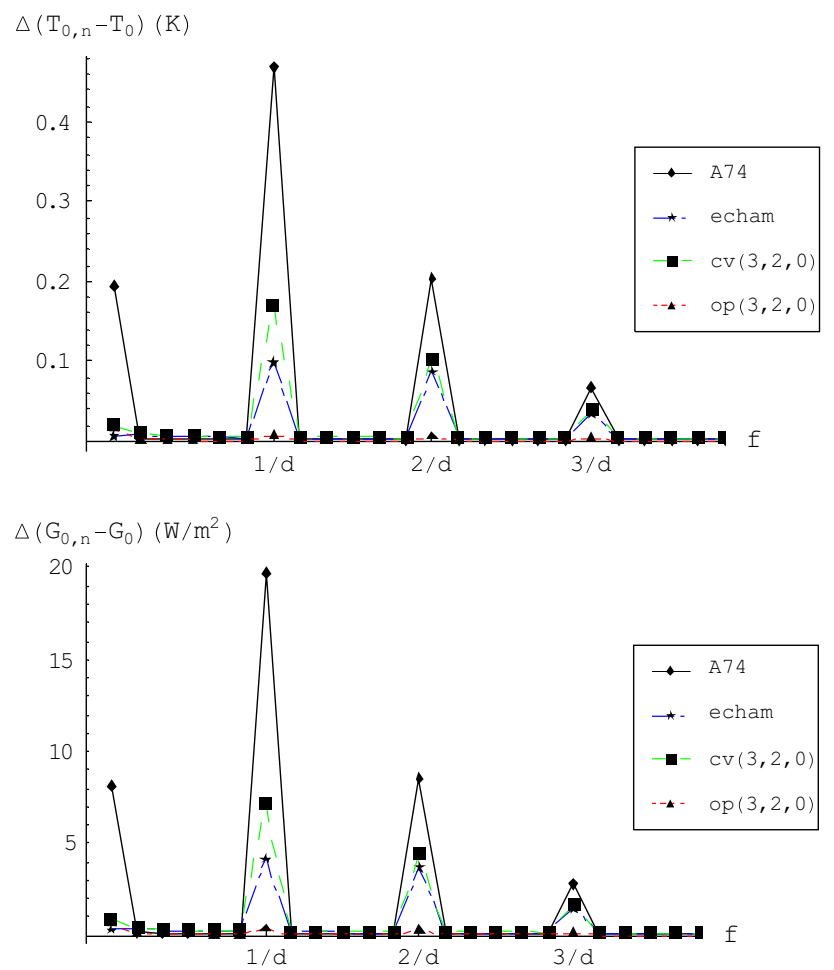

Fig. 8 Same as Fig. 7, but these differences between numerical solution and analytical solution are expressed in the frequency spectrum

of Cases $1-4$ by "op $(5,0,0)$ " are at about $0.8 \%$, but the errors increase to about $16 \%$ for Cases 5-7. In contrast, those for Cases $5-7$ by "op $(3,2,0)$ " are only $2 \%$. Note that "op $(3,2,0)$ " consists two layers for recording the annual profile of ground temperature. Therefore, it is necessary to allocate a few layers of $z_{k}$ to simulate the annual frequency component properly. Nonetheless, in respect to the sunspot frequency component, which is in Case 7, it shows that the normalized overall error $e\left(G_{0}^{*}\right)$ of $\operatorname{op}(3,2,1)$ for Case 7 is only slightly better than that of "op $(3,2,0)$ " by $0.01 \%$ (or $0.004 \mathrm{~W} \mathrm{~m}^{-2}$ ). Therefore, allocation of an additional layer for recording sun-spot frequency is not crucial for having accuracy at $1 \mathrm{~W} \mathrm{~m}^{-2}$ for $G_{0}$ simulation.

\subsection{Lag-predict problem of snow melting time}

The lag-predict of snow melting time has been found in many state-of-the-art models (e.g., Arpe et al. 1994; Link and Marks 1999). One likely reason is caused by the "cv" scheme used for their snow ST simulation. Figure 9 shows the STs simulated by the "cv" schemes of various discretizations ("cv(1,1,0)", “cv(2,1,0)", “cv(3,2,0)") and by the "op(3,2,0)" scheme, suggested by this study. It can be seen that all the "cv" schemes underestimate the range of ST. They systematically underestimate the ST during the day and overestimate it during the night. Since snow usually melts during the day, therefore, the "cv" scheme can produce a time lag for snowmelt simulation. Besides, the underestimation increases with the numerical thickness $h_{0}$ of the skin layer. The "cv(1,1,0)" scheme, of which $h_{0}$ is $0.91 \mathrm{~m}$, underestimates the ST by $4 \mathrm{~K}$ at noon, while " $\operatorname{cv}(3,2,0)$ ", of which $h_{0}$ is $0.064 \mathrm{~m}$, underestimates it by $0.5 \mathrm{~K}$. In contrast, the "op(3,2,0)" scheme accurately predicts the ST with RMSE at $0.02 \mathrm{~K}$. Therefore, the error of the time-lag problem in snowmelt simulation can be reduced.

\subsection{Other effective thickness}

The above section shows that setting effective thicknesses of the skin layer at the optimal effective thicknesses is the most accurate for ST simulation. Nonetheless, there are uncertainties with the value for $\partial G_{0} / \partial T_{0}$ although it is suggested using a typical value of $42 \mathrm{~W} \mathrm{~m}^{-2} \mathrm{~K}^{-1}$ (the annual median value of a cropland site in Bondville, USA) for the purpose. Here, various effective thicknesses are derived.

For example, under two extreme elasticities $\left(s^{*} \rightarrow 0\right.$, $s^{*} \rightarrow \infty$ ), i.e., (the non-stiff condition and the stiff

Table 7 Same as Table 6 but for the overall normalized RMSE error $\left(e\left(G_{0}^{*}\right)\right)(\%)$ for surface ground heat flux simulation of various schemes for 7 cases (as listed in Table 5)

\begin{tabular}{|c|c|c|c|c|c|c|c|c|c|c|c|c|}
\hline $\begin{array}{l}\text { Levels } \\
\text { Scheme } \\
\text { case }\end{array}$ & $\begin{array}{l}\text { STD } \\
\left(\mathrm{W} \mathrm{m} \mathrm{m}^{-2}\right)\end{array}$ & $\begin{array}{l}1 \\
o p(0,0,0)\end{array}$ & $\begin{array}{l}2 \\
\text { op }(1,0,0)\end{array}$ & $\begin{array}{l}3 \\
\text { op }(2,0,0)\end{array}$ & $\begin{array}{l}4 \\
\text { op }(3,0,0)\end{array}$ & $\begin{array}{l}5 \\
\text { op }(4,0,0)\end{array}$ & $\begin{array}{l}6 \\
\text { op }(5,0,0)\end{array}$ & $\begin{array}{l}3 \\
\text { op }(1,1,0)\end{array}$ & $\begin{array}{l}4 \\
o p(2,1,0)\end{array}$ & $\begin{array}{l}5 \\
\text { op }(3,1,0)\end{array}$ & $\begin{array}{l}6 \\
\text { op }(3,2,0)\end{array}$ & $\begin{array}{l}7 \\
\text { op }(3,2,1)\end{array}$ \\
\hline 1 & 39.20 & 67.59 & 14.25 & 4.75 & 2.05 & 1.09 & 0.71 & 13.09 & 4.33 & 1.80 & 1.43 & 1.43 \\
\hline 2 & 42.02 & 67.89 & 13.44 & 4.51 & 2.02 & 1.14 & 0.77 & 12.41 & 4.15 & 1.81 & 1.52 & 1.52 \\
\hline 3 & 42.31 & 67.93 & 13.46 & 4.54 & 2.05 & 1.15 & 0.78 & 12.44 & 4.18 & 1.84 & 1.56 & 1.56 \\
\hline 4 & 42.37 & 67.92 & 13.48 & 4.56 & 2.05 & 1.16 & 0.78 & 12.47 & 4.20 & 1.85 & 1.57 & 1.57 \\
\hline 5 & 42.96 & 69.59 & 22.88 & 18.60 & 17.52 & 16.85 & 16.31 & 12.75 & 5.26 & 3.54 & 2.08 & 2.07 \\
\hline 6 & 42.96 & 69.81 & 23.49 & 19.30 & 18.22 & 17.53 & 16.97 & 12.76 & 5.28 & 3.57 & 2.09 & 2.08 \\
\hline 7 & 42.97 & 69.51 & 22.66 & 18.34 & 17.26 & 16.60 & 16.06 & 12.75 & 5.26 & 3.54 & 2.08 & 2.07 \\
\hline
\end{tabular}



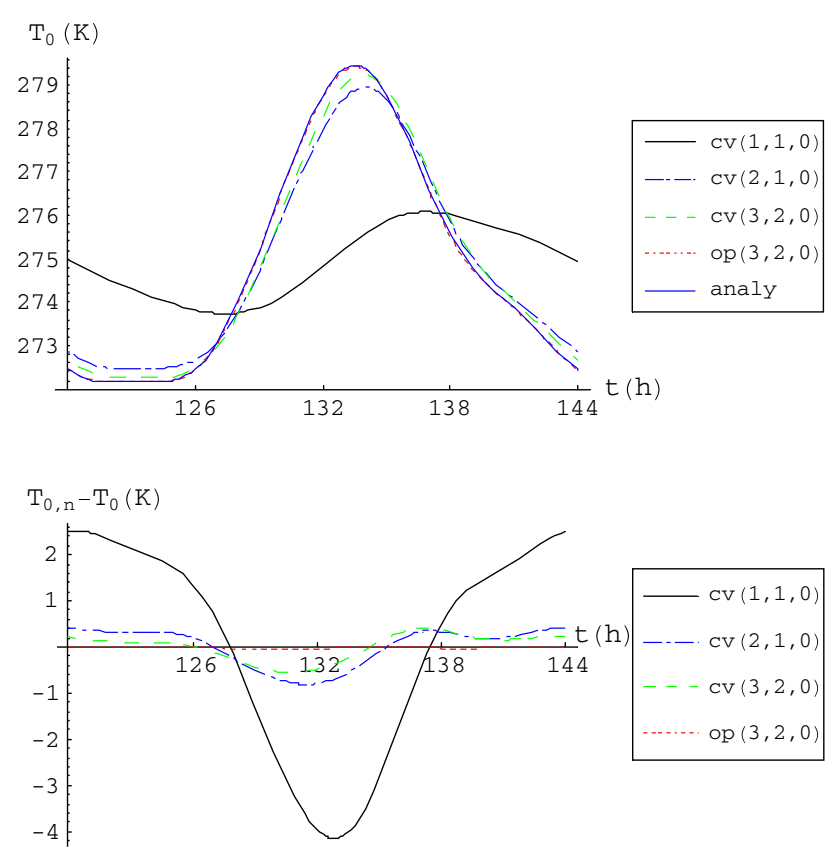

Fig. 9 Same as Fig. 7, but for the last day of the simulation (day 6) among "cv( $(1,1,0)$ ", “cv( $2,1,0)$ ", “cv( $3,2,0) "$ and “op(3,2,0)", of which the physics thicknesses $h_{0}$ of the skin layers are $0.91,0.098$, 0.064 and $0.019 \mathrm{~m}$, respectively

condition), the effective thickness $h_{e 0}^{*}$ of the skin layer can be derived from Eq. 21 as:

$h_{e 0}^{n *}=\lim _{s_{0}^{*} \rightarrow 0} h_{e 0}^{p *}=\frac{h_{a 0}^{*}}{\cos \left(t_{a 0}^{*}\right)}$

$h_{e 0}^{s *}=\lim _{s_{0}^{*} \rightarrow \infty} h_{e 0}^{p *}=\cos \left(t_{a 0}^{*}\right) h_{a 0}^{*}$

where the first superscripts of $h_{e 0}^{n^{*}}$ and $h_{e 0}^{s^{*}}$ denote the optimal thickness derived under the "non-stiff" and "stiff" conditions, respectively. We name the effective thickness $h_{e 0}^{n *}$ as the optimal non-stiff thickness, and denote the numerical scheme, which sets $h_{e 0}^{*}=h_{e 0}^{n *}$, as "on". And, we name the thickness $h_{e 0}^{s^{*}}$ as the optimal stiff thickness, and denote the numerical scheme, which sets $h_{e 0}^{*}=h_{e 0}^{s^{*}}$, as "os". In addition, From the above two equations, it can be seen that $h_{e 0}^{n^{*}}>h_{a 0}^{*}>h_{e 0}^{s^{*}}$. Since $h_{a 0}^{*}$ is also not a function of $\partial G_{0}^{*} / \partial T_{0}^{*}$, therefore, setting $h_{e 0}^{*}$ at $h_{a 0}^{*}$, is another choice for the effective thickness. We name the numerical scheme, which sets $h_{e 0}^{*}=h_{a 0}^{*}$, as the non-stiff equal-amplitude scheme (denoted as "ne") since its simulated amplitude of ST of the concerned frequency component $j$ is equal to its true amplitude $\left(\Delta T^{*}=\sqrt{2}\right)$ under the non-stiff condition according to Eq. 61 .

Figure 3 also shows the accuracies of the "ne", "on" and "os" schemes as functions of $h_{0}^{*}$ under $\partial G_{0}^{*} / \partial T_{0}^{*}=4$ and 0.5 . Table 8 lists the equations for determining the effective thickness of various schemes ("cv", "nh", "ne", "on", "os" and "op") and their corresponding accuracies.
The $e\left(g_{0}^{*}\right)$ of the "ne", "on" and "os" schemes are calculated from Eq. 24 by setting $h_{e 0}^{*}$ at $h_{e 0}^{n^{*}}$ and $h_{e 0}^{s^{*}}$, respectively. This figure shows that calculating STs of a particular frequency component using the schemes of "op" "ne", "on" and "os" are always better than "cv" and "nh". In addition, for high $\partial G_{0}{ }^{*} / \partial T_{0}^{*}(=4$ in this case study), the accuracy of "os" is the closest to "op"; but for low $\partial G_{0}^{*} / \partial T_{0}^{*}(=0.5$ in this case study), the accuracy of "on" is the closest to "op". Moreover, the figure shows that for both high and low $\partial G_{0}^{*} / \partial T_{0}^{*}$, the accuracy simulated by "ne" is only slightly worse than "op". Therefore, the "ne" scheme is a good scheme for implementing to models for which $\partial G_{0}^{*} / \partial T_{0}^{*}$ is not immediately available. It can be shown that "A74" is a special case of "ne" for $h_{0}^{*} \rightarrow \infty$, and "D78" is a special case of "on" for $h_{0}^{*} \rightarrow \infty$.

\subsection{Adding the skin layer onto the conventional finite} difference scheme "cv + op"

Table 6 also shows that "ecmwf + op" is better than "ecmwf", and "echam + op" is better than "echam". For Case 7, $e\left(G_{0}^{*}\right)$ of "ecmwf + op" is at $10 \%$ while that of "ecmwf" is at $11 \%$, and $e\left(G_{0}^{*}\right)$ of "echam + op" $15 \%$ while that of "echam" is at $19 \%$. This shows that using the optimal effective thickness for the skin layer also improves the model system for surface ground heat flux simulation for both the state-of-the-art models "ECMWF" and "ECHAM". This "cv + op" type scheme can be important for a land type such as ocean which is not suitable for using the effective thicknesses for all the ground layers, or for a model of which the model structure does not want to be changed significantly. In addition to being more accurate than "cv", the benefits of using "cv + op" or " $\mathrm{cv}+$ ne" include: (1) keeping track of the energy budget of a land column in the layer-mean temperatures of a land column, and (2) retaining the same memory allocation system of most climate models. Note that most of the models store $\mathrm{ST}$ as well as the layer-mean temperatures of a land column [e.g., ECMWF (Viterbo and Beljaars 1995), ECHAM (Roeckner et al. 2003), and NCEP (Kanamitsu et al. 2002)]. The scheme "cv + ne" proposed in this study has been used for a turbulent kinetic energy ocean model (Tu and Tsuang 2005).

\section{Conclusion}

This study introduces a differential equation for calculating skin temperature, and derives the optimal effective thickness analytically by minimizing the error for the temperature simulation at each numerical layer. The optimal effective thickness of each numeral layer can be determined from Eq. 20. It shows that the effective 
Table 8 Characteristics of various effective thickness parameterizations for skin layer

\begin{tabular}{|c|c|c|c|c|c|c|c|c|}
\hline \multirow[t]{2}{*}{ Abbr } & \multirow[t]{2}{*}{ Name } & \multicolumn{2}{|l|}{ General } & \multicolumn{2}{|l|}{$h_{0}^{*} \rightarrow 0$} & \multicolumn{3}{|c|}{$h_{0}^{*} \rightarrow \infty$} \\
\hline & & $h_{e 0}^{*}$ & $e\left(g_{0}^{*}\right)$ & $h_{e 0}^{*}$ & $\frac{e\left(g_{0}^{*}\right)}{\left(\partial G_{0}^{*} / \partial T_{0}^{*}\right) / k_{0}^{*}}$ & $h_{e 0}^{*}$ & $e\left(g_{0}^{*}\right)$ & $\lim _{\partial G_{0} / \partial T_{0} \rightarrow \infty} e\left(g_{0}^{*}\right)$ \\
\hline $\mathrm{cv}$ & $\begin{array}{l}\text { Conventional } \\
\text { finite- } \\
\text { difference } \\
\text { scheme }\end{array}$ & $h_{0}^{*}$ & $\frac{\partial G_{0}^{*}}{\partial T_{0}^{*}} \sqrt{\frac{h_{0}^{* 2}-2 \cos \left(t_{a 0}^{*}\right) h_{a 0}^{*} h_{0}^{*}+h_{a 0}^{* 2}}{h_{0}^{* 2}+0.5 k_{0}^{* 2}}}$ & $h_{0}^{*}$ & $h_{0}^{* 2}-\frac{h_{0}^{* 3}}{3}$ & $h_{0}^{*}$ & $\frac{\partial G_{0}^{*}}{\partial T_{0}^{*}}$ & $\infty$ \\
\hline $\mathrm{nh}$ & $\begin{array}{l}\text { No heat } \\
\text { capacity } \\
\text { scheme }\end{array}$ & 0 & $\frac{\partial G_{0}^{*}}{\partial T_{0}^{*}} \frac{\sqrt{2} h_{a 0}^{*}}{k_{0}^{*}}$ & 0 & $\begin{array}{l}\sqrt{2} h_{0}-0.5 \sqrt{2} h_{0}^{*} \\
+0.125 \sqrt{2} h_{0}^{* 3}\end{array}$ & 0 & 1 & $100 \%$ \\
\hline ne & $\begin{array}{l}\text { Non-stiff equal- } \\
\text { amplitude } \\
\text { scheme }\end{array}$ & $h_{a 0}^{*}($ Eq. 15) & $\frac{\partial G_{0}^{*}}{\partial T_{0}^{*}} \sqrt{\frac{2-2 \cos \left(t_{a 0}^{*}\right)}{1+0.5 k_{0}^{* 2} / h_{a 0}^{* 2}}}$ & $\begin{array}{l}h_{0}^{*}-0.5 h_{0}^{* 2} \\
+0.125 h_{0}^{* 3}\end{array}$ & $\frac{h_{0}^{* 2}}{\sqrt{2}}-\frac{\sqrt{2}}{3} h_{0}^{* 3}$ & $\begin{array}{l}1 / \sqrt{2} \\
(\mathrm{~A} 74)\end{array}$ & $\sqrt{\frac{2-\sqrt{2}}{1+\left(\partial G_{0}^{*} / \partial T_{0}^{*}\right)^{2}}} \frac{\partial G_{0}^{*}}{\partial T_{0}^{*}}$ & $\begin{array}{l}\sqrt{2-\sqrt{2}} \\
\quad(76 \%)\end{array}$ \\
\hline on & $\begin{array}{l}\text { Optimal non- } \\
\text { stiff scheme }\end{array}$ & $\begin{array}{l}h_{a 0}^{*} / \cos \left(t_{a 0}^{*}\right) \\
\quad\left(\text { or } h_{e 0}^{n *}\right)\end{array}$ & $\frac{\sin \left(t_{a 0}^{*}\right)\left(\partial G_{0}^{*} / \partial T_{0}^{*}\right)}{\sqrt{1+0.5 \cos \left(t_{a 0}^{*}\right)^{2} k_{0}^{* 2} / h_{a 0}^{* 2}}}$ & $\begin{array}{l}h_{0}^{*}-0.5 h_{0}^{* 2} \\
\quad+0.25 h_{0}^{* 3}\end{array}$ & $\frac{h_{0}^{* 2}}{\sqrt{2}}-\frac{\sqrt{2}}{3} h_{0}^{* 3}$ & $\begin{array}{l}1 \\
\text { (D78) }\end{array}$ & $\sqrt{\frac{1}{2+\left(\partial G_{0}^{*} / \partial T_{0}^{*}\right)^{2}}} \frac{\partial G_{0}^{*}}{\partial T_{0}^{*}}$ & $100 \%$ \\
\hline os & $\begin{array}{l}\text { Optimal stiff } \\
\text { scheme }\end{array}$ & $\begin{array}{l}h_{a 0}^{*} \cos \left(t_{a 0}^{*}\right) \\
\quad\left(\text { or } h_{e 0}^{s^{*}}\right)\end{array}$ & $\frac{\sin \left(t_{a 0}^{*}\right)\left(\partial G_{0}^{*} / \partial T_{0}^{*}\right)}{\sqrt{\cos \left(t_{* a}^{*}\right)^{2}+0.5 k_{0}^{* 2} / h^{* 2}}}$ & $\begin{array}{c}h_{0}^{*}- \\
0.5 h_{0}^{* 2}\end{array}$ & $\frac{h_{0}^{* 2}}{\sqrt{2}}-\frac{\sqrt{2}}{3} h_{0}^{* 3}$ & 0.5 & $\sqrt{\frac{1}{1+2\left(\partial G_{0}^{*} / \partial T_{0}^{*}\right)^{2}}} \frac{\partial G_{0}^{*}}{\partial T_{0}^{*}}$ & $\sqrt{1 / 2}(71 \%)$ \\
\hline op & Optimal scheme & $\begin{array}{l}h_{e 0}^{p^{*}} \\
\quad \text { (Eq. 21) }\end{array}$ & $\frac{\partial G_{0}^{*}}{\partial T_{0}^{*}} \sqrt{\frac{h_{e 0}^{h-2}-2 \cos \left(t_{a 0}^{*} h_{a 0}^{*} h_{e 0}^{h e}+h_{a 0}^{* 2}\right.}{h_{e 0}^{p+2}+0.5 k_{0}^{* 2}}}$ & $h_{0}^{*}-0.5 h_{0}^{* 2}$ & $\frac{h_{0}^{* 2}}{\sqrt{2}}-\frac{\sqrt{2}}{3} h_{0}^{* 3}$ & $0.5 p$ & $\sqrt{\frac{1}{2}} \frac{\partial G_{0}^{*}}{\partial T_{0}^{*}} \sqrt{\frac{p+2 q}{p+q}}$ & $\sqrt{1 / 2}(71 \%)$ \\
\hline
\end{tabular}

Here $h_{e 0}^{*}$ is the nondimensional effective thickness of the skin layer of a frequency component, and $e\left(\mathrm{~g} 0^{*}\right)$ is the normalized root-mean-square error (NRMSE) (or RMSE/STD ratio) of the calculated surface ground heat flux of the frequency component compared to the true flux $p=1-\left(\partial G_{0}^{*} / \partial T_{0}^{*}\right)^{2}+\sqrt{1+\left(\partial G_{0}^{*} / \partial T_{0}^{*}\right)^{4}} ; q=\left(\partial G_{0}^{*} / \partial T_{0}^{*}\right)^{4}-\left(\partial G_{0}^{*} / \partial T_{0}^{*}\right)^{2}\left(\sqrt{1+\left(\partial G_{0}^{*} / \partial T_{0}^{*}\right)^{4}}\right)$

thickness is always thinner than its physical thickness. The value of the effective thickness $h_{e 0}^{p}$ of the skin layer is a function of its physical thickness $h_{0}$ and the temperature derivate $\partial G_{0} / \partial T_{0}$ of surface ground heat flux (Fig. 4). The value of $h_{e 0}^{p}$ approaches to $h_{0}$ when $h_{0} \rightarrow 0$, and $h_{e 0}^{p}$ is fixed at a range within $\left(0.5 \sqrt{2 D / \omega_{d}}, \sqrt{2 D / \omega_{d}}\right)$, varying with $\partial G_{0} / \partial T_{0}$, when $h_{0} \rightarrow \infty$. Therefore, the assumptions of low or no heat capacity (i.e., $h_{e 0} \ll h_{0}$ ) for the skin layer when $h_{0} \rightarrow 0$ are not good approximations for a homogeneous ground column. Nonetheless, it may be valid where the land surface is covered by vegetation or it consists of organic soil, of which the heat diffusivity is usually much lower than that of the underneath soil (Best 1998). The characteristics such as the thickness and the accuracies of the various effective thicknesses ("cv", "nh", "ne", "on", "os" and "op"), especially under $h_{0}^{*} \rightarrow 0$ and $h_{0}^{*} \rightarrow \infty$, are listed in Table 8.

The most beneficial scheme is "op". Table 4 lists the vertical discretizations of the "op" scheme of 1-6 numerical levels for calculating Earth's skin temperature. The suggested discretization is derived from the evenly heatcontent discretization with the optimal effective thickness for layer-temperature simulation. For the same level number, the suggested discretization is more accurate in skin temperature as well as surface ground heat flux simulations than those used in some state-of-the-art models. The proposed scheme ("op $(3,2,0)$ ") has shown to be more accurate than the schemes used in state-of-art climate models including ECMWF (Viterbo and Beljaars 1995), ECHAM
(Roeckner et al. 2003) and the UCLA GCM (Arakawa and Mintz 1974). The profiles of diurnal and annual ground temperatures are recoded in the middle layers of "op $(3,2,0)$ ". This type of arrangement is important for reducing the error of the corresponding frequency component. In addition, it is found that "cv" systematically underestimates ST during the day. The underestimation can be as high as $4 \mathrm{~K}$ for $h_{0}$ at $0.91 \mathrm{~m}$. Since snow usually melts during the day, the "cv" scheme can cause a time lag for snowmelt. In contrast, the "op $(3,2,0)$ " scheme, proposed by this study, accurately predicts the ST with RMSE at $0.02 \mathrm{~K}$. Therefore, the error in the time lag can be reduced. Nonetheless, it should be noted that we are not able to prove the evenly heat-content discretization to be the optimal vertical discretization. A better vertical discretization may exist. A tri-diagonal matrix for solving the temperatures by the "op" scheme is illustrated in the Appendix 4.

The introduction of an additional differential equation for calculating skin temperature is also found beneficial for the temperature simulation. For the same vertical structure $(3,2,0)$, "cv + op" is better than "cv + nh", and "cv $+\mathrm{nh}$ " is better than "cv". In addition, "ecmwf + op" is better than "ecmwf", and "echam + op" is better than "echam" (Table 6). Although the proposed "op" scheme can be easily implemented into state-of-the-art climate models for the temperature simulation of snow, ice sheet and soil, nonetheless, it should be reminded that the effective thickness is derived based on the assumption that heat source is from the surface only. If horizontal advected 
heat flux is important, such as for ocean water temperature simulation, "cv + op" can be a better option than "op". In addition, the introduction of effective thickness for each numerical layer, which is different from the real layer thickness, causes the energy conservation equation to be different from the conventional form. From Eq. 1, it can be easily proved that the heat content $H(\mathrm{~J})$ of an entire ground column from infinite depth $(z=-\infty)$ to the surface $(z=0)$ can be determined using a modified form as:

$$
\frac{\partial H}{\partial t}=\frac{\partial}{\partial t}\left(\int_{-\infty}^{0} \rho_{g} c_{g} T \mathrm{~d} z\right)=\frac{\partial}{\partial t}\left(\sum_{k=0}^{m} \rho_{g} c_{g} T_{k} h_{e k}\right)
$$

Acknowledgments This work is supported by NSC/Taiwan under contracts 95-2111-M-005-001, 95-2621-Z-005-004, 96-2111-M-005001-MY3 and 96-2621-Z-005-001. Thanks to Noel Dallow and Dr. A. Alagesan for proofreading. We are grateful to the National Center for High-performance Computing/Taiwan for computer time and facilities The Bondville data is obtained from AmeriFlux web site (http://public.ornl.gov/ameriflux/).

Open Access This article is distributed under the terms of the Creative Commons Attribution Noncommercial License which permits any noncommercial use, distribution, and reproduction in any medium, provided the original author(s) and source are credited.

\section{Appendix 1: Analytical ground temperature and heat flux equations}

Considering an ideal surface, in which the heat diffusion coefficient is constant and neglecting the horizontal heat transport, the heat transfer in the ground can be assumed to obey the Fourier law of diffusion (e.g., Hillel 1982) as:

$\frac{\partial T}{\partial t}=\frac{-1}{\rho_{g} c_{g}} \frac{\partial G}{\partial z}=\frac{\partial}{\partial z} D \frac{\partial T}{\partial z}=D \frac{\partial^{2} T}{\partial z^{2}}$

and

$G=-\rho_{g} c_{g} D \frac{\partial T}{\partial z}$

where $T$ is ground temperature $(\mathrm{K}), t$ is time (s), $G$ is ground heat flux $\left(\mathrm{W} \mathrm{m}^{-2}\right.$ ) (positive upward), $D$ is heat diffusivity of ground surface $\left(\mathrm{m}^{2} \mathrm{~s}^{-1}\right)$, and $z$ is the vertical coordinate system $(m)$ (positive upward).

Considering the upper boundary temperature (denoted as $T_{\mathrm{s}}$ ) at $z=0$, i.e., the upper boundary condition of Eq. 33, can be described in the frequency domain (e.g., Tsuang 2003) as:

$T_{s}=\overline{T_{s}}+\sum_{j=1}^{j=\infty} \Delta T_{s j} \cos \left(\omega_{j}\left(t-t_{m j}\right)\right)$

where the overbar " " " is the average, the subscript " $j$ " denotes a property of frequency component $j, \Delta T_{s j}$ is the amplitude of $T_{\mathrm{s}}$ of the particular frequency component, $\omega_{j}$ is the angular velocity of the frequency component, $t_{m j}$ is the time when the highest $T_{\mathrm{s}}$ of the particular frequency component occurs, and $t$ is local time.

The analytical solution of the temperature profile of Eq. 33 can be determined (after Carslaw and Jaeger 1959) as:

$$
\begin{aligned}
T(z, t)= & \overline{T_{s}}+\sum_{j=1}^{j=\infty} \Delta T_{s j} \exp \left(\sqrt{\frac{\omega_{j}}{2 D}} z\right) \\
& \times \cos \left(\omega_{j}\left(t-t_{m j}\right)+\sqrt{\frac{\omega_{j}}{2 D}} z\right)=\sum_{j=0}^{j=\infty} \tau_{j}(z, t)
\end{aligned}
$$

where $\tau_{j}$ is the ground temperature of frequency component $j$. For $j=0, \tau_{0}=\overline{T_{s}}$. For $j \geq 1, \tau_{j}$ can be determined by observing the second equality of the above equation as

$$
\tau_{j}(z, t)=\Delta T_{s j} \exp \left(\sqrt{\frac{\omega_{j}}{2 D}} z\right) \cos \left(\omega_{j}\left(t-t_{m j}\right)+\sqrt{\frac{\omega_{j}}{2 D}} z\right)
$$

Note that Carslaw and Jaeger (1959) only proved the above solution (A4) with a single frequency component. Nonetheless, the above form (A4) is also valid for multiple frequency components. It can be proven by substituting the above equation to Eq. 33 to check the equality between the right hand side (RHS) and the left hand side (LHS) of Eq. 33.

Substituting the above equation into Eq. 34, the analytical solution of ground heat flux can be determined as:

$$
\begin{aligned}
G(z, t)= & \sum_{j=1}^{j=\infty}-\rho_{g} c_{g} \Delta T_{s j} \sqrt{D \omega_{j}} \exp \left(\sqrt{\frac{\omega_{j}}{2 D}} z\right) \\
& \times \cos \left(\omega_{j}\left(t-t_{m j}\right)+\sqrt{\frac{\omega_{j}}{2 D}} z+\frac{\pi}{4}\right) \\
= & \sum_{j=0}^{j=\infty} g_{j}(z, t)
\end{aligned}
$$

where $g_{j}$ is the ground heat flux of frequency component $j$. For $j=0, g_{0}=0$. For $j \geq 1, g_{j}$ can be determined by observing the second equality of the above equation as

$g_{j}(z, t)=-\Delta g_{j} \exp \left(\sqrt{\frac{\omega_{j}}{2 D}} z\right) \cos \left(\omega_{j}\left(t-t_{m j}\right)+\sqrt{\frac{\omega_{j}}{2 D}} z+\frac{\pi}{4}\right)$

and

$\Delta g_{j} \equiv \rho_{g} c_{g} \Delta T_{s j} \sqrt{D \omega_{j}}$

From the above equation, the dominant frequency component can be identified by choosing the maximum value among $\Delta g_{j}$ of various frequency components $j$.

The STD of $T_{\mathrm{s}}$ of frequency component $j$ (denoted as $\left.\tau_{j \mathrm{STD}}\right)$ can be determined from Eq. 36 as: 


$$
\tau_{0 j \mathrm{STD}} \equiv \sqrt{\overline{\left(\tau_{j}(0, t)-\overline{\tau_{j}(0, t)}\right)^{2}}}=\frac{1}{\sqrt{2}} \Delta T_{s j}
$$

And the STD of surface ground heat flux, where $z=0$, of the frequency component (denoted as $g_{j \mathrm{STD}}$ ) can be determined from Eq. 39 as:

$$
\begin{aligned}
g_{0 j \mathrm{STD}} & \equiv \sqrt{\overline{\left(g_{j}(0, t)-\overline{g_{j}(0, t)}\right)^{2}}}=\sqrt{\frac{1}{2} \Delta g_{j}^{2}} \\
& =\frac{\rho_{g} c_{g} \sqrt{D \omega_{j}} \Delta T_{s j}}{\sqrt{2}}=\rho_{g} c_{g} \sqrt{D \omega_{j}} \tau_{j \mathrm{STD}}
\end{aligned}
$$

\section{Appendix 2: Temperature derivative of ground heat flux}

This appendix shows the form of the temperature derivative of ground heat flux $\partial G / \partial T$. $G_{0}$ can be determined from the energy budget of the land surface (positive upward) (e.g., Brutsaert 1982) as:

$G_{0}=-\left[(1-\alpha) R_{s}+R_{\mathrm{ld}}-R_{\mathrm{lu}}-H-\mathrm{LE}\right]$

where $\alpha$ is albedo, $R_{\mathrm{s}}$ is incoming solar radiation (positive downward), $R_{\mathrm{ld}}$ is incoming atmospheric radiation (positive downward), $R_{\text {lu }}$ is outgoing terrestrial radiation (positive upward), $H$ is surface sensible heat flux (positive upward) and LE is surface latent heat flux (positive upward). $R_{\text {lu }}, H$ and LE are functions of ST. They can be determined (e.g., Brutsaert 1982; Garratt 1992) as:

$R_{\mathrm{lu}}=\varepsilon \sigma T_{0}^{4}$

$H=\frac{\rho_{a} c_{a}}{r_{a}}\left(T_{0}-T_{a}\right)$

$\mathrm{LE}=\frac{\rho_{a} L_{v}}{r_{a}+r_{c}}\left(q^{*}\left(T_{0}\right)-q_{a}\right)$

where $\varepsilon$ is emissivity of surface; $\sigma$ is Stefan-Boltzman constant $\left(\sim 5.67 \times 10^{-8} \mathrm{~W} \mathrm{~m}^{-2} \mathrm{~K}^{-4}\right) ; \rho_{\mathrm{a}}, c_{\mathrm{a}}, T_{\mathrm{a}}$ and $q_{\mathrm{a}}$ are density $\left(\sim 1.16 \mathrm{~kg} \mathrm{~m}^{-3}\right)$, constant pressure heat capacity $\left(\sim 1,005 \mathrm{~J} \mathrm{~kg}^{-1} \mathrm{~K}^{-1}\right)$, temperature $(\mathrm{K})$ and specific humidity $\left(\mathrm{kg} \mathrm{kg}^{-1}\right)$ of air, respectively; $q^{*}(T)$ is saturated specific humidity at temperature $T\left(=0.622 e^{*}(T) /\right.$ $P$ ), where $P$ is atmospheric pressure $(\mathrm{Pa})$ and $e^{*}$ is saturated vapor pressure $(\mathrm{Pa})$ (Richards 1971); $r_{\mathrm{a}}$ is aerodynamic resistance $\left(\mathrm{s} \mathrm{m}^{-1}\right) ; r_{\mathrm{c}}$ is canopy resistance $\left(\mathrm{s} \mathrm{m}^{-1}\right)$ for evapotranspiration; and $L_{\mathrm{v}}$ is latent heat of evaporation $\left(\sim 2.5 \times 10^{6} \mathrm{~J} / \mathrm{kg}\right)$. Substituting the above three equations into Eq. $43, G_{0}$ can be written as a function of ST as:

$$
\begin{aligned}
G_{0}\left(T_{0}\right)=- & {\left[(1-\alpha) R_{s}+R_{\mathrm{ld}}-\varepsilon \sigma T_{0}^{4}-\frac{\rho_{a} c_{a}}{r_{a}}\left(T_{0}-T_{a}\right)\right.} \\
& \left.-\frac{\rho_{a} L_{v}}{r_{a}+r_{c}}\left(q^{*}\left(T_{0}\right)-q_{a}\right)\right]
\end{aligned}
$$

The above equation shows surface ground heat flux is a function of ST. Therefore, $\partial G_{0} / \partial T_{0}$ can be derived by taking the derivative of the above equation on ST as:

$\frac{\partial G_{0}\left(T_{0}\right)}{\partial T_{0}}=4 \varepsilon \sigma T_{0}^{3}+\frac{\rho_{a} c_{a}}{r_{a}}+\frac{\rho_{a} L_{v}}{r_{a}+r_{c}} \frac{\partial q^{*}\left(T_{0}\right)}{\partial T_{0}}$

In addition, from Eq. 34, the ground heat flux at level $k$ can be determined conventionally by the finite difference scheme (Fig. 1) as:

$G_{k}=-\rho_{g} c_{g} D \frac{T_{k-1}-T_{k}}{z_{k-1}-z_{k}}+$ H.O.T.

Therefore, $\partial G_{k} / \partial T_{k-1}$ and $\partial G_{k} / \partial T_{k}$ can be derived by taking the derivative of the above equation on $T_{k-1}$ and $T_{k}$ as:

$\frac{\partial G_{k}}{\partial T_{k-1}}=-\frac{\rho_{g} c_{g} D}{z_{k-1}-z_{k}}=-s_{k}$

$\frac{\partial G_{k}}{\partial T_{k}}=\frac{\rho_{g} c_{g} D}{z_{k-1}-z_{k}}$

\section{Appendix 3: Nondimensionalization and optimal effective thickness}

To derive a general form for a particular frequency component $j \geq 1$, equations of the frequency component are made nondimensional, by multiplying time by the angular velocity $\omega_{j}$ of the frequency component, dividing the length by $\sqrt{2 D / \omega_{j}}$, dividing energy flux by the STD of the ground heat flux component $g_{k j}$ at the upper boundary $(\zeta=0)$, i.e., $g_{k j \mathrm{STD}}$, and dividing temperature component $\tau_{k j}$ by its STD at the upper boundary $(\zeta=0)$, i.e., $\tau_{k j \mathrm{STD}}$. In addition denoting nondimensional quantities of the frequency component with asterisks, but without the level index $k$ and the frequency index $j$ for simplicity (although occasionally we will recover these indices $k$ and $j$ in the text for clarity), we obtain:

$\tau^{*} \equiv \frac{\tau_{k j}}{\tau_{k j \mathrm{STD}}}=\frac{\sqrt{2} \tau_{k j}}{\Delta T_{s k j}}, \quad t^{*} \equiv \omega_{j} t$,

$g^{*} \equiv \frac{g_{k j}}{g_{k j \mathrm{STD}}}=\frac{\sqrt{2} g_{k j}}{\rho_{g} c_{g} \sqrt{D \omega_{j}} \Delta T_{s k j}}, \quad \zeta^{*} \equiv \frac{\zeta}{\sqrt{2 D / \omega_{j}}}$

where $\quad \tau_{k j \mathrm{STD}}=\Delta T_{s k j} / \sqrt{2} \quad$ and $\quad g_{k j \mathrm{STD}}=\rho_{g} c_{g} \sqrt{D \omega_{j}}$ $\Delta T_{s k j} / \sqrt{2}$ according to Eqs. 41 and 42 , respectively. As a result, the dimensionless forms of the analytical solution (Eq. 37) of the ground temperature of the frequency component and its analytical solution (Eq. 39) of the ground heat flux profile of the component can be rewritten using dimensionless variables as:

$\tau^{*}\left(\zeta^{*}, t^{*}\right)=\sqrt{2} \exp \left(\zeta^{*}\right) \cos \left(t^{*}-t_{m}^{*}+\zeta^{*}\right)$ 
$g^{*}\left(\zeta^{*}, t^{*}\right)=-\sqrt{2} \exp \left(\zeta^{*}\right) \cos \left(t^{*}-t_{m}^{*}+\zeta^{*}+\frac{\pi}{4}\right)$

Note that from Eq. 53, it can be seen that the amplitude of the true dimensionless skin temperature component $\tau^{*}$ is $\sqrt{2}$. And the dimensionless forms of $\partial G_{0} / \partial T_{0}$ and the elasticity $s_{k}$ can be written as:

$$
\begin{aligned}
x_{0}^{*} & =\frac{\partial G_{0}^{*}}{\partial T_{0}^{*}}=\frac{\tau_{0 j \mathrm{STD}}}{g_{0 j \mathrm{STD}}} \frac{\partial G_{0}}{\partial T_{0}}=\frac{1}{\rho_{g} c_{g} \sqrt{D \omega_{j}}} \frac{\partial G_{0}}{\partial T_{0}} \\
x_{k}^{*} & =-\frac{\partial G_{k}^{*}}{\partial T_{k-1}^{*}}=\frac{\partial G_{k}^{*}}{\partial T_{k}^{*}}=\frac{\rho_{g} c_{g} D}{\rho_{g} c_{g} \sqrt{D \omega_{j}}\left(z_{k-1}-z_{k}\right)} \\
& =\frac{1}{\sqrt{2}\left(z_{k-1}^{*}-z_{k}^{*}\right)}, \quad k=1, \mathrm{~m} \\
x_{m+1}^{*} & =0
\end{aligned}
$$

and

$s^{*} \equiv x_{k}^{*}+x_{k+1}^{*}$

where the second equalities are derived by substituting Eqs. 41 and 42 into 5. The above Eq. 55a implies that if $\partial G_{0} / \partial T_{0}$ remains constant, the lower the frequency, the higher the value of $\partial G_{0}^{*} / \partial T_{0}^{*}$ will be, i.e., approaching the stiff condition.

In addition, the dimensionless form of the governing Eq. 10 for determining $T_{k}$ of the frequency component by a numerical method can be derived by multiplying it by $\sqrt{2} / \omega_{j} \Delta T_{s k j}$. The form, then, can be written as:

$$
\begin{aligned}
& \frac{\partial \tau_{n}^{*}}{\partial t^{*}}+\frac{s^{*}}{\sqrt{2} h_{e}^{*}} \tau_{n}^{*}=-\frac{1}{\sqrt{2} h_{e}^{*}}\left[g^{*}\left(0, t^{*}\right)-g^{*}\left(-h^{*}, t^{*}\right)-s^{*} \tau^{*}\left(-h_{t}^{*}, t^{*}\right)\right] \\
& =\frac{1}{\sqrt{2} h_{e}^{*}}\left[\begin{array}{l}
\sqrt{2} \cos \left(t^{*}-t_{m}^{*}+\frac{\pi}{4}\right)-\sqrt{2} \exp \left(-h^{*}\right) \\
\cos \left(t^{*}-t_{m}^{*}-h^{*}+\frac{\pi}{4}\right) \\
+\sqrt{2} s^{*} \exp \left(-h_{T}^{*}\right) \cos \left(t^{*}-t_{m}^{*}-h_{t}^{*}\right)
\end{array}\right] \\
& =-\sqrt{2} \frac{h_{a}^{*}}{h_{e}^{*}} \sin \left(t^{*}-t_{m}^{*}-t_{a}^{*}\right)+\frac{s^{*}}{h_{e}^{*}} \exp \left(-h_{T}^{*}\right) \cos \left(t^{*}-t_{m}^{*}-h_{t}^{*}\right)
\end{aligned}
$$

where $h^{*} \equiv h_{k} / \sqrt{2 D / \omega_{j}}$. Note that the second equality is derived by substituting Eqs. 53 and 54 into it, which assumes that the ground heat fluxes at the surface and at depth $h_{k}$ are accurately provided as inputs. And,

$$
\begin{aligned}
& h_{a}^{*}\left(h^{*}\right)=\frac{1}{\sqrt{2}} \sqrt{1-2 \cos \left(h^{*}\right) \exp \left(-h^{*}\right)+\exp \left(-h^{*}\right)^{2}} \\
& t_{a}^{*}\left(h^{*}\right)=\frac{\pi}{4}-\tan ^{-1}\left(\frac{\exp \left(-h^{*}\right) \sin \left(h^{*}\right)}{1-\exp \left(-h^{*}\right) \cos \left(h^{*}\right)}\right)
\end{aligned}
$$

Under the condition that $s^{*}$ is constant, Eq. 57 is a firstorder linear ordinary differential equation with constant coefficients (e.g., Kreyszig 2006), which can be solved analytically as:

$$
\begin{aligned}
\tau_{n}^{*}= & \frac{1}{2 h_{e}^{* 2}+s^{* 2}}\left[2 \sqrt{2} h_{a}^{*} h_{e}^{*} \cos \left(t^{*}-t_{m}^{*}-t_{a}^{*}\right)\right. \\
& -2 s^{*} h_{a}^{*} \sin \left(t^{*}-t_{m}^{*}-t_{a}^{*}\right)+\sqrt{2} s^{* 2} \exp \left(-h_{t}^{*}\right) \\
& \left.\cos \left(t^{*}-t_{m}^{*}-h_{t}^{*}\right)+2 s^{*} h_{e}^{*} \exp \left(-h_{t}^{*}\right) \sin \left(t^{*}-t_{m}^{*}-h_{t}^{*}\right)\right] \\
= & \Delta T_{n}^{*} \cos \left(t^{*}-t_{m}^{*}-t_{l}^{*}\right)
\end{aligned}
$$

where $\Delta T_{n}{ }^{*}$ and $t_{l}^{*}$ are the amplitude and the phase lag of the simulated $T_{k, n}$ of the frequency component. They are

$\Delta T_{n}^{*}=\sqrt{2} \sqrt{\frac{2 h_{a}^{* 2}+2 \sqrt{2} \sin \left(t_{a}^{*}-h_{t}^{*}\right) h_{a}^{*} s^{*} \exp \left(-h_{t}^{*}\right)+s^{* 2} \exp \left(-h_{t}^{*}\right)^{2}}{2 h_{e}^{* 2}+s^{* 2}}}$

$t_{l}^{*}=\tan ^{-1}\left[\begin{array}{l}2 \sqrt{2} h_{a}^{*} h_{e}^{*} \sin \left(t_{a}^{*}\right)-2 s^{*} h_{a}^{*} \cos \left(t_{a}^{*}\right) \\ \frac{-\sqrt{2} s^{* 2} \exp \left(-h_{t}^{*}\right) \sin \left(-h_{t}^{*}\right)+2 s^{*} h_{e}^{*} \exp \left(-h_{t}^{*}\right) \cos \left(-h_{t}^{*}\right)}{2 \sqrt{2} h_{a}^{*} h_{e}^{*} \cos \left(t_{a}^{*}\right)+2 s^{*} h_{a}^{*} \sin \left(t_{a}^{*}\right)} \\ +\sqrt{2} s^{* 2} \exp \left(-h_{t}^{*}\right) \cos \left(-h_{t}^{*}\right)+2 s^{*} h_{e}^{*} \exp \left(-h_{t}^{*}\right) \sin \left(-h_{t}^{*}\right)\end{array}\right]$

As a result, the difference (denoted as $\varepsilon\left(\tau^{*}\right)$ ) between calculated $T_{k, n}$ and the true $T_{k}$ of the frequency component can be written as a cosine function from Eqs. 60 and 53 as:

$$
\begin{aligned}
& \varepsilon\left(\tau^{*}\right) \equiv \tau_{n}^{*}-\tau^{*}\left(h_{t}^{*}, t^{*}\right) \\
& =\frac{1}{2 h_{e}^{* 2}+s^{* 2}}\left[\begin{array}{l}
2 \sqrt{2} h_{a}^{*} h_{e}^{*} \cos \left(t^{*}-t_{m}^{*}-t_{a}^{*}\right)-2 s^{*} h_{a}^{*} \sin \left(t^{*}-t_{m}^{*}-t_{a}^{*}\right) \\
+\sqrt{2} s^{* 2} \exp \left(-h_{t}^{*}\right) \cos \left(t^{*}-t_{m}^{*}-h_{t}^{*}\right) \\
+2 s^{*} h_{e}^{*} \exp \left(-h_{t}^{*}\right) \sin \left(t^{*}-t_{m}^{*}-h_{t}^{*}\right)
\end{array}\right] \\
& -\sqrt{2} \exp \left(-h_{t}^{*}\right) \cos \left(t^{*}-t_{m}^{*}-h_{t}^{*}\right) \\
& =\Delta T_{\varepsilon}^{*} \cos \left(t^{*}-t_{m}^{*}-t_{\varepsilon}^{*}\right)
\end{aligned}
$$

where the second equality is derived by substituting Eqs. 60 and 53 into it, and $\Delta T_{\varepsilon}^{*}$ and $t_{\varepsilon}^{*}$ are determined as:

$$
\Delta T_{\varepsilon}^{*}=2 \sqrt{\frac{h_{a}^{* 2}-2 h_{a}^{*} h_{e}^{*} \exp \left(-h_{t}^{*}\right) \cos \left(t_{a}^{*}-h_{t}^{*}\right)+\exp \left(-h_{t}^{*}\right)^{2} h_{e}^{* 2}}{2 h_{e}^{* 2}+s^{* 2}}}
$$

$$
t_{\varepsilon}^{*}=\tan ^{-1}\left[\begin{array}{l}
2 \sqrt{2} h_{a}^{*} h_{e}^{*} \sin \left(t_{a}^{*}\right)-2 s^{*} h_{a}^{*} \cos \left(t_{a}^{*}\right) \\
\frac{\sqrt{2} \exp \left(-h_{t}^{*}\right) 2 h_{e}^{* 2} \sin \left(-h_{t}^{*}\right)+2 s^{*} h_{e}^{*} \exp \left(-h_{t}^{*}\right) \cos \left(-h_{t}^{*}\right)}{2 \sqrt{2} h_{a}^{*} h_{e}^{*} \cos \left(t_{a}^{*}\right)+2 s^{*} h_{a}^{*} \sin \left(t_{a}^{*}\right)} \\
-\sqrt{2} \exp \left(-h_{t}^{*}\right) 2 h_{e}^{* 2} \cos \left(-h_{t}^{*}\right)+2 s^{*} h_{e}^{*} \exp \left(-h_{t}^{*}\right) \sin \left(-h_{t}^{*}\right)
\end{array}\right]
$$

Therefore, the normalized root-mean-square error (NRMSE) (or RMSE/STD ratio) $e\left(\tau^{*}\right)$ of the calculated $T_{k, n}$ of the frequency component compared to the true $T_{k}$ can be determined from Eq. 63 as: 


$$
\begin{aligned}
& e\left(\tau^{*}\right) \equiv \sqrt{\overline{\left(\tau_{n}^{*}-\tau^{*}\left(h_{t}^{*}, t^{*}\right)\right)^{2}}}=\sqrt{\overline{\varepsilon\left(\tau^{*}\left(h_{t}^{*}, t^{*}\right)\right)^{2}}} \\
& =\sqrt{\overline{\left[\Delta T_{\varepsilon}^{*} \cos \left(t^{*}-t_{m}^{*}-t_{\varepsilon}^{*}\right)\right]^{2}}}=\sqrt{0.5 \Delta T_{\varepsilon}^{* 2}} \\
& =\sqrt{\frac{h_{a}^{* 2}-2 h_{a}^{*} h_{e}^{*} \exp \left(-h_{t}^{*}\right) \cos \left(t_{a}^{*}-h_{t}^{*}\right)+\exp \left(-h_{t}^{*}\right)^{2} h_{e}^{* 2}}{h_{e}^{* 2}+0.5 s^{* 2}}}
\end{aligned}
$$

where the fourth equality is derived, since $\overline{\cos \left(t^{*}-t_{m}^{*}-t_{\varepsilon}^{*}\right)^{2}}=0.5$. It shows that $e\left(\tau^{*}\right)$ is a function of $h^{*}, h_{e}^{*}, h_{t}^{*}$ and $s^{*}$ only. Note that $h_{a}^{*}$ and $t_{a}^{*}$ are functions of $h^{*}$ according to Eqs. 58 and 59 .

In order to minimize the NRMSE $\tau^{*}$, the optimal effective thickness $h_{e}^{*}$ can be determined by taking the derivative of $e\left(\tau^{*}\right)$ from Eq. 66 and letting:

$\frac{\partial e\left(\tau^{*}\right)}{\partial h_{e}^{*}}=0$

Solving the above equation, the optimal value of $h_{e}^{*}$ (denoted as $h_{e}^{p^{*}}$ ) is determined as:

\section{Appendix 4: Numerical matrix for the "optimal" scheme}

This appendix describes the numerical parameterization in this study. A numerical grid is chosen to discretize the land column as shown in Fig. 1. That is, $T$ is determined at the center of the grid, and flux $G_{k}$ is determined at the boundaries of the grid. The ST and the ground temperature of each layer are parameterized according to Eq. 27. The resulting temperature matrix is:

$h_{e}^{p *}=\frac{2 h_{a}^{* 2}-\exp \left(-h_{t}^{*}\right)^{2} s^{* 2}+\sqrt{4 h_{a}^{* 4}+4 \cos 2\left(t_{a}^{*}-h_{t}^{*}\right) \exp \left(-h_{t}^{*}\right)^{2} h_{a}^{* 2} s^{* 2}+\exp \left(-h_{t}^{*}\right)^{4} s^{* 4}}}{4 \cos \left(t_{a}^{*}-h_{t}^{*}\right) \exp \left(-h_{t}^{*}\right) h_{a}^{*}}$

where the negative value is discarded.

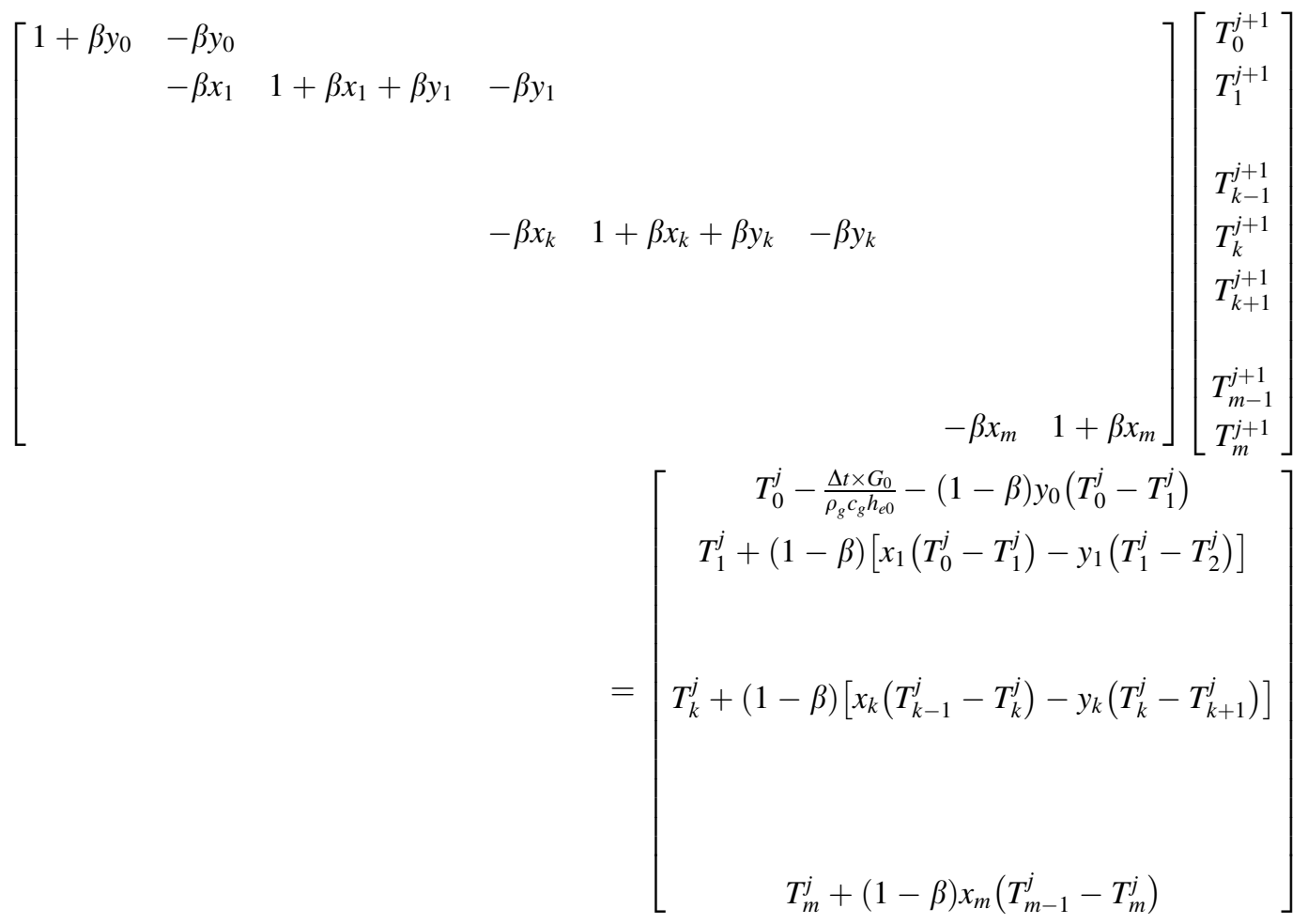


where the variables in Eq. 69 are described as follows:

$y_{0}=\frac{\Delta t}{h_{e 0}} \frac{D}{z_{0}-z_{1}}$

$x_{k}=\frac{\Delta t}{h_{e k}}\left(\frac{D}{z_{k-1}-z_{k}}\right), \quad$ for $k=1, m-1$

$y_{k}=\frac{\Delta t}{h_{e k}}\left(\frac{D}{z_{k}-z_{k+1}}\right), \quad$ for $k=1, m-1$

$x_{m}=\frac{\Delta t D}{h_{e m}\left(z_{m-1}-z_{m}\right)}$

where the coordinates $z_{k}$ are listed in Table 4, varying with discretization chosen, and the effective thickness of $h_{e k}$ is parameterized according to Eq. 20. The values of $h_{k}$ and $h_{t k}$ is determined as:

$$
\begin{aligned}
& h_{0}=0.5\left(z_{0}-z_{1}\right), \\
& h_{k}=0.5\left(z_{k-1}-z_{k+1}\right), \quad \text { for } k=1, m-1 \\
& h_{t 0}=0 \\
& h_{t k}=0.5\left(z_{k-1}-z_{k}\right), \quad \text { for } k=1, m
\end{aligned}
$$

Note that $\beta=0$ for the forward scheme, $\beta=0.5$ for the Crank-Nicolson scheme, and $\beta=1$ for the backward scheme. The backward scheme is found to be desirable since it is numerical unconditionally stable, and the backward scheme has been implemented into a climate model (Tsuang et al. 2001). The matrix is a tri-diagonal matrix and can be easily and efficiently solved by the LU method (e.g., Press et al. 1992).

\section{References}

Arakawa A, Mintz Y (1974) The UCLA atmospheric general circulation model. Notes distributed at the workshop 25 March-4 April 1974. Department of Meteorology, University of California, Los Angeles, p 90024

Arpe K, Bengtsson L, Dumenil L, Roeckner EE (1994) The hydrological cycle in the ECHAM3 simulations of the atmospheric circulation. In: Desbois M, Desalmand F (eds) Global precipitations and climate change, vol I 26. NATO ASI Series, pp 361-377

Best MJ (1998) A model to predict surface temperatures. Bound Layer Meteorol 88(2):279-306. doi:10.1023/A:1001151927113

Blondin C (1991) Parameterization of land-surface processes in numerical weather prediction. In: Schmugge TJ, Andre JC (eds) Land surface evaporation: measurement and parameterization. Springer, Berlin, pp 31-54

Bowling LC et al (2003) Simulation of high-latitude hydrological processes in the Torne-Kalix basin: PILPS phase 2(e) - 1: Experiment description and summary intercomparisons. Glob Planet Change 38:1-30

Brutsaert WH (1982) Evaporation into the Atmosphere. D. Reidel Publish Company, Holland, p 299

Carslaw HS, Jaeger JC (1959) Conduction of heat in solids, 2nd edn. Oxford Press, NY, p 509
Chen F, Dudhia J (2001) Coupling an advanced land surfacehydrology model with the Penn State-NCAR MM5 modeling system. Part I: model implementation and sensitivity. Mon Weather Rev 129:569-585. doi:10.1175/1520-0493(2001)129 $<0569$ :CAALSH $>2.0 . \mathrm{CO} ; 2$

Chia HH, Wu C-C (1998) Air-sea eddy fluxes and the mixed layer of the western equatorial pacific: observation and one-dimensional model simulation. Atmos Sci 26(2):157-179 (in Chinese)

de Vries DA (1975) Heat transfer in soils, in heat and mass transfer in the biosphere. In: de Vries DA, Afgan NH (eds) Scripta, Washington, DC, pp 5-28

Deardorff JW (1978) Efficient prediction of ground surface temperature and moisture, with inclusion of a layer of vegetation. J Geophys Res 83:1889-1903. doi:10.1029/JC083iC04p01889

Dickinson RE, Oleson KW, Bonan G, Hoffman F, Thornton P, Vertenstein M, Yang ZL, Zeng X (2006) The community land model and its climate statistics as a component of the community climate system model. J Clim 19:2302-2324. doi:10.1175/ JCLI3742.1

Ek MB, Mitchell KE, Lin Y, Rogers E, Grunmann P, Koren V, Gayno G, Tarpley JD (2003) Implementation of Noah land surface model advances in the National Centers for Environmental Prediction operational mesoscale Eta model. J Geophys Res 108(D22):8851. doi:10.1029/2002JD003296

Garratt JR (1992) The atmospheric boundary layer. Cambridge University Press, London, p 316

Gaspar P, Gregoris Y, Lefevre J-M (1990) A simple eddy kinetic energy model for simulations of the oceanic vertical mixing: Test at station Papa and long-term upper ocean study site. J Geophys Res 95:16179-16193. doi:10.1029/JC095iC09p16179

Grell G, Dudhia J, Stauffer D (1995) A description of the fifthgeneration Penn State/NCAR Mesoscale Model (MM5). NCAR TECHNICAL NOTE NCAR/TN-398 + STR

Henderson-Seller A (1995) The project for intercomparison of landsurface parameterization schemes (PILPS)-phase-2 and phase-3. Bull Am Meteorol Soc 76:489-503. doi:10.1175/1520-0477 (1995)076<0489:TPFIOL $>2.0$. CO;2

Hillel D (1982) Introduction to soil physics. Academic Press, London, p 364

Hostetler SW, Bates GT, Giorgi F (1993) Interactive coupling of a lake thermal model with a regional climate model. J Geophys Res 98:5045-5057. doi:10.1029/92JD02843

Huang S, Pollack HN, Shen P-Y (2000) Temperature trends over the past five centuries reconstructed from borehole temperatures. Nature 403:756-758. doi:10.1038/35001556

Jarvis PG, McNaughton KG (1986) Stomatal control of transpiration: scaling up from leaf to region. Adv Ecol Res 15(15):1-49. doi: 10.1016/S0065-2504(08)60119-1

Kanamitsu M, Ebisuzaki W, Woollen J, Yang S-K, Hnilo JJ, Fiorino M, Potter GL (2002) NCEP-DOE AMIP-II Reanalysis (R-2). Bull Am Meteorol Soc 83(11):1631-1643. doi:10.1175/BAMS83-11-1631(2002)083<1631:NAR $>2.3$.CO;2

Kreyszig E (2006) Advanced engineering mathematics, 9th edn. Wiley, New York, p 1094 + appendix

Link TE, Marks D (1999) Point simulation of seasonal snow cover dynamics beneath boreal forest canopies. J Geophys Res 104(D22):27841-27858. doi:10.1029/1998JD200121

Luo LF et al (2003) Effects of frozen soil on soil temperature, spring infiltration, and runoff: results from the PILPS 2(d) experiment at Valdai, Russia. J Hydrometeorol 4:334-351

Meyers TP, Hollinger SE (2004) An assessment of storage terms in the surface energy balance of maize and soybean. Agric For Meteorol 125:105-115. doi:10.1016/j.agrformet.2004.03.001

Mote P, O'Neill A (2000) Numerical modeling of the global atmosphere in the climate system, Springer, New York, p 517 
Oleson KW, Dai Y, Bonan GB, Bosilovich M, Dickinson R, Dirmeyer P, Hoffman F, Houser P, Levis S, Niu G-Y, Thornton P, Vertenstein M, Yang Z-L, Zeng X (2004) Technical description of the Community Land Model (CLM). Technical Report NCAR/TN-461 + STR, National Center for Atmospheric Research, Boulder, CO. 80307-3000, p 174

Press WH, Teukolsky SA, Vetterling WT, Flannery BP (1992) Numerical Recipes in Fortran. Cambridge University Press, London, p 963

Ramaswamy V, Boucher O, Haigh J, Hauglustaine D, Haywood J, Myhre G, Nakajima T, Shi GY, Solomon S (2001) Radiative forcing of climate change. In: Houghton JT, Ding Y, Griggs DJ, Noguer M, van der Linden PJ, Dai X, Maskell K, Johnson CA (eds) Climate change 2001: the scientific basis. Contribution of working group I to the third assessment report of the intergovernmental panel on climate change. Cambridge University Press, Cambridge, p 881

Richards JM (1971) Simple expression for the saturation vapor pressure of water in the range $-50^{\circ} \mathrm{C}$ to $140^{\circ} \mathrm{C}$. Br J Appl Phys 4:L15-L18

Roeckner E, Baeuml G, Bonventura L, Brokopf R, Esch M, Giorgetta M, Hagemann S, Kirchner I, Kornblueh L, Manzini E, Rhodin A, Schlese U, Schulzweida U, Tompkins A (2003) The atmospheric general circulation model ECHAM 5. PART I: model description, Report 349, Max Planck Institute for Meteorology, Hamburg, Germany. Available from http://www.mpimet.mpg.de

Schlosser CA et al (2000) Simulations of a boreal grassland hydrology at Valdai, Russia: PILPS phase 2(D). Mon Weather Rev 128:301-321

Sellers P, Mintz Y, Sud Y, Dalcher A (1986) A simple biosphere model $(\mathrm{SiB})$ for use within general circulation models. J Atmos Sci 43(6):505-531. doi:10.1175/1520-0469(1986)043<0505: ASBMFU $>2.0 . \mathrm{CO} ; 2$

Sellers P, Randall D, Collatz G, Berry J, Field C et al (1996) A revised land surface parameterization $(\mathrm{SiB} 2)$ for atmospheric GCMS. Part I: model formulation. J Clim 9(4):676-705. doi:10.1175/1520-0442(1996)009<0676:ARLSPF>2.0.CO;2

Shuttleworth WJ et al (1984) Eddy correlation measurements of energy partition for Amazonian forest. Q J R Meteorol Soc 110:1143-1162. doi:10.1002/qj.49711046622

Simmons AJ, Gibson JK (eds) (2000) The ERA40 Project plan, Eur. Cent. For Med.-Range Weather Forecasts, Reading, UK, ECMWF Rep Ser 1, p 62

Slater AG et al (2001) The representation of snow in land surface schemes: results from PILPS 2(d). J Hydrometeorol 2:7-25

Tsai J-L, Tsuang B-J, Lu P-S, Yao M-H, Shen Y (2007) Surface energy components and land characteristics of a rice paddy. J Appl Meteorol Climatol 46(11):1879-1900
Tsuang B-J (2003) Analytical asymptotic solutions to determine interactions between the planetary boundary layer and the Earth's surface. J Geophys Res Atmos 108(D16):8608. doi: 10.1029/2002JD002557

Tsuang B-J (2005) Ground heat flux determination according to land skin temperature observations from in-situ stations and satellites. J Hydrometeorol 6(4):371-390. doi:10.1175/JHM425.1

Tsuang B-J, Dracup JA (1990) An energy-based snowmelt runoff model for an alpine watershed, EOS transactions, American Geophysical Union, vol 71, No 43, H41-10, Presented at AGU 1990 Fall Meeting, San Francisco, p 1335

Tsuang B-J, Yuan H-C (1994) The ideal numerical surface thickness to determine ground surface temperature and schemes comparison. Atmos Sci 21:189-218 (in Chinese)

Tsuang B-J, Tu C-Y (2002) Model structure and land parameter identification: an inverse problem approach. J Geophys Res Atmos 107(D10):4096. doi:10.1029/2001JD000711

Tsuang B-J, Tu C-Y, Arpe K (2001) Lake parameterization for climate models. Max-Planck-Institute for Meteorology Rept. \# $316, \mathrm{p} 72$

Tsuang B-J, Chou M-D, Zhang Y, Roesch A, Yang K (2008) Evaluations of land-ocean skin temperatures of the ISCCP satellite retrievals and the NCEP and ERA reanalyses. J Clim 21:308-330. doi:10.1175/2007JCLI1502.1

Tu C-Y, Tsuang B-J (2005) Cool-skin simulation by a one-column ocean model. Geophys Res Lett 32:L22602. doi:10.1029/2005 GL024252

Van den Hurk B, Viterbo P (2003) The Torne-Kalix PILPS 2(e) experiment as a test bed for modifications to the ECMWF land surface scheme. Global Planet Change 38:165-173. doi: 10.1016/S0921-8181(03)00027-4

Verma SB, Baldocchi DD, Anderson DE, Matt DR, Clement RJ (1986) Eddy fluxes of $\mathrm{CO}_{2}$, water vapor, and sensible heat over a deciduous forest. Bound Layer Meteorol 36:71-91. doi: 10.1007/BF00117459

Viterbo P, Beljaars ACM (1995) An improved land surface parametrization scheme in the ECMWF model and its validation. J Clim 8:2716-2748. doi:10.1175/1520-0442(1995)008<2716: AILSPS $>2.0 . \mathrm{CO} ; 2$

Wilson KB, Baldocchi DD, Aubinet M, Berbigier P, Bernhofer C, Dolman H, Falge E, Field C, Goldstein A, Granier A, Grelle A, Halldor A, Hollinger D, Katul G, Law BE, Lindroth A, Meyers A, Moncrieff J, Monson R, Oechel W, Tenhunen J, Valetini R, Verma S, Vesala T, Wofsy S (2002) Energy partitioning between latent and sensible heat flux during the warm season at FLUXNET sites. Water Resour Res 38:1294. doi:10.1029/ 2001WR000989 